Journal of Global Economic Analysis, Volume 4 (2019), No. 1, pp. 50-96.

\title{
G-RDEM: A GTAP-Based Recursive Dynamic CGE Model for Long-Term Baseline Generation and Analysis
}

\author{
BY WOLFGANG BRITZa AND ROBERTO ROSON ${ }^{\mathrm{b}}$
}

We motivate and detail the new GTAP-based recursive dynamic economic model (G-RDEM), a computable general equilibrium tool for long-term counterfactual analysis and baseline generation from given gross domestic product (GDP) and population projections. It encompasses an implicitly directly additive demand system (AIDADS) demand system with non-linear Engel curves, debt accumulation from foreign saving and introduces sector specific productivity changes, endogenous aggregate saving rates, as well as time-varying cost shares for value added and individual intermediates. Parameters for these relationships are econometrically estimated or taken from published work. The core of the model is derived from the Global Trade Anaylsis Project (GTAP) standard model and seamlessly incorporated into the modular and flexible CGEBox modelling platform, allowing for combined applications with various other extensions, such as GTAPagro-ecological zones (AEZ) or GTAP-Water. G-RDEM maintains the flexible aggregation from the GTAP Data Base. It is open source, encoded in General Algebraic Modelling System (GAMS) and can be steered by a Graphical User Interface, which also encompasses a tool to analyse results with tables, graphs and maps. Existing GDP and population projections from the Socio-Economic Pathways (SSP) 1-5 can be directly incorporated for baseline construction. A comparison of the generated long-term structural composition of the economy against a simple recursive-dynamic variant, derived from the standard GTAP model, shows that GRDEM brings about much more plausible results, as well as a more realistic, internally consistent representation of the economic structure in a hypothetical future.

JEL codes: C68, C82, D58, E17, F43.

a Institute for Food and Resource Economics, University of Bonn, Nussallee 21, D-53115 Bonn, Germany (e-mail: wolfgang.britz@ilr.uni-bonn.de).

b Ca' Foscari University, Cannaregio 873 I-30121 Venice Italy; GREEN Bocconi University, Milan; Loyola Andalusia University, Seville (e-mail: roson@unive.it). 
Keywords: Computable General Equilibrium Models; Long-run Economic Scenarios; Structural Change.

\section{Background and introduction}

Due to issues such as climate change and depletion of global resources, there is an increasing demand for long-term quantitative analyses. Computable general equilibrium (CGE) models can contribute in that direction as they consistently consider the manifold interrelations occurring in the economy, while providing the often needed sectoral detail. They therefore complement approaches working at a more aggregate level (e.g. Dellink et al., 2017) or focusing in detail on specific sectors (e.g. Alexandratos and Bruinsma, 2012).

However, it should be noted that CGE models were not originally designed to this purpose, but rather for short-term policy assessment, like simulating the effects of a fiscal reform, or the implementation of a trade agreement. Accordingly, most parameters are usually "calibrated" to a relatively recent Social Accounting Matrix or Input Output Table, such that the observed structure of an economic system is taken as a benchmark, from which counterfactual experiments are conducted. Practitioners working with CGEs therefore face the problem of how to make their models suitable for long-run analysis and, more specifically, of how to construct a long-term baseline, normally based on given GDP and population projections. The GTAP-based Recursive-Dynamic Economic Model (G-RDEM) addresses these needs and our paper presents and discusses the main elements of that new tool, and presents some some illustrative simulation exercises.

Of course, when the economy is analysed at a horizon of 20,30, or even more years, the economic structure, as emerging from some past national accounts, which may refer to five years back, is no longer a valid starting point. One should consider trends in structural adjustment, driven by changing preferences, demographic composition, new technologies, variations in the endowments of primary resources (including human capital), etc. The whole issue is not about forecasting: nobody actually knows which "breakthrough" technologies could emerge, or which unexpected phenomena could shape the economic structure in the future. What we do know from past observations is that a number of "slow" adjustment processes, meaning steady variations occurring over time and across regions at various stages of economic development, are active and therefore they should be taken into account in the generation of a credible and internally consistent future baseline.

The study of the time evolution of the economic structure ("structural change") is a rather active research field in theoretical and applied economics (Matsuyama, 2008). Most of the studies in the literature, however, look at the past. Typical research questions are: the contribution of the changing industrial mix to aggregate productivity (e.g., Duarte and Restuccia, 2010); the declining share of the agricultural sector in developing economies (e.g., Üngör, 2013), etc., where 
some specific transition processes are identified. Here, rather than studying the past, we aim at drawing from some empirical findings and methodologies in this literature to infer, inside a CGE modelling framework, a possible future evolution of the economy.

To this end, a number of "unconventional" features have to be introduced into the standard CGE formulation, to create a model specifically designed for the generation and assessment of long-term economic scenarios. We present therefore in here a newly develop CGE model of this kind, termed G-RDEM. This model considers drivers of long run structural change, which we regard as especially relevant, namely: (1) non-linear Engel curves in household consumption, (2) productivity growth differentiated by sector, (3) debt accumulation from foreign savings and trade imbalances, (4) aggregate saving rates linked to population and income dynamics, and (5) time-varying and income dependent industrial cost shares. While other recursive-dynamic CGE models partly consider these features, we are not aware of a model that encompasses all of them all.

G-RDEM extends the flexible and modular CGE modelling platform CGEBox (Britz and Van der Mensbrugghe, 2018), from which it inherits some important features. Firstly, the code is open source, to ensure transparency and invite the community of modellers to use the tool and contribute to its further development. This principle also applied to G-RDEM, allowing contributors, for instance, to refine further elements in the parameterization of the model depending on economic development. Secondly, it maintains full flexibility in sectoral and regional aggregation. Thirdly, as a seamless integrated module into CGEBox, GRDEM offers the possibility to combine it with other modules such as carbon dioxide $\left(\mathrm{CO}_{2}\right)$ and Non- $\mathrm{CO}_{2}$ emissions, GTAP-Water, GTAP-Agro-Ecological Zones (AEZ) etc.. Hence, G-RDEM as part of CGEBox can be used to construct baselines drawing on the GTAP standard model (Corong et al., 2018; van der Mensbrugghe, 2018) as a kind of "out-of-the-box" approach for subsequent counterfactual recursive-dynamic analysis. Alternatively, as shown in Britz and van der Mensbrugghe (2018) for the comparative-static case, CGEBox can be used to configure a CGE model with specific features and additional modules. Adding some or all features of G-RDEM allows then to deploy the configured CGE for recursive-dynamic work, giving the seasoned modeler a high degree of flexibility with regard to model layout, including the possibility to develop additional recursive-dynamic features. Application of G-RDEM is facilitated by the fact that the population and GDP projections up to 2100 for the five Shared Socio Economic Pathways (SSPs) from the International Institute for Applied Systems Analysis (IIASA) SSPs Database are distributed in a directly usable format with the code.

All the new features are based on econometrically estimated parameters. GRDEM is encoded in the GAMS modelling language and, as a module of CGEBox, shares its graphical user interface. This paper and the supplementary materials, 
which allow readers to replicate the results in this manuscript, also aim at a fully documented and transparent model implementation. ${ }^{1}$

\section{Overview}

The construction of a long-term baseline in CGE models typically draws on population and GDP projections from other studies. Indeed, most applications of CGE models in recursive-dynamic fashion only consider capital accumulation as an endogenous mechanism driving growth, while productivity changes and other drivers of structural change are usually kept exogenous. In order to let a CGE model replicate a given growth path, a total factor productivity shifter is endogenously determined during the construction of the reference baseline, by fixing GDP at each time period. In subsequent model runs and counterfactual simulations, productivity parameters are then maintained at those estimated levels, while national income is endogenously computed.

This simple methodology aligns the output of the CGE model to a predetermined aggregate growth path, but of course does not capture some fundamental structural changes which may take place inside the economy, i.e. in the composition of output and demand. Instead, we aim in here to address the key elements driving such compositional change (Figure 1 ).

To this end, we introduce an implicitly directly additive demand system (AIDADS) demand system to consider how budget shares in household consumption adjust to the changing levels of per capita income, to capture "nonlinear Engel curves", which are a salient feature of economic development. Secondly, the economy wide total factor productivity (TFP) shifter, aligning the model to the target GDP in any period, is here differentiated by sector. These two features are introduced through specific equations directly into the CGE system itself (red boxes in Figure 1). Other elements are activated in between the solution points (blue boxes). Therefore, the intra-period equilibrium computed by the model, in combination with exogenous projections from the current period $t$, updates some parameters for the following period $t+1$. The labour force (by skill category) is adjusted to population and work force projections. Next year's capital stocks reflect last year's ending stocks and gross investments. International capital transfers reflect past foreign savings. Saving rates adjust to population and GDP growth, and I-O coefficients (factor shares in production processes) are updated on the basis of national income.

${ }^{1}$ The supplementary material comprises the GAMS codes used to replicate the results reported in this paper. The code of both G-RDEM and CGEBox is under further development which includes correcting errors reported by users. We therefore suggest users to maintain an up-to-date version of CGEBox, including G-RDEM, by using SVN as detailed in the supplementary material. 


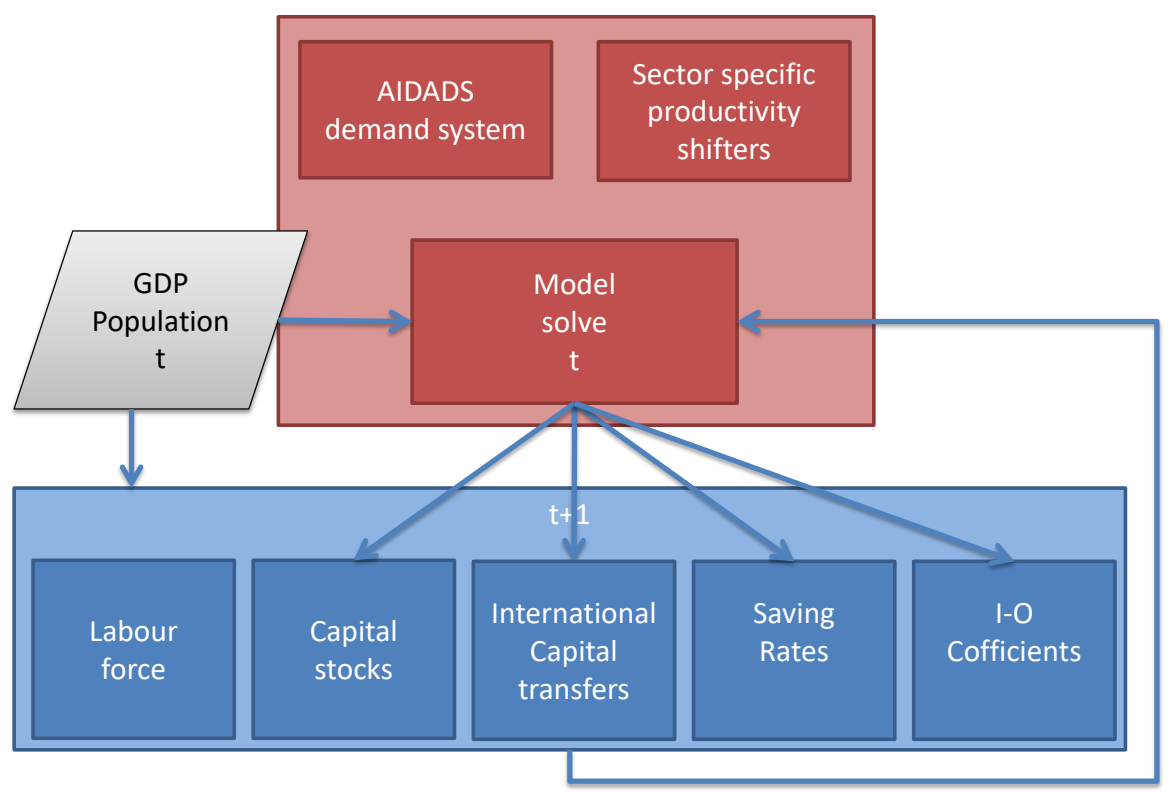

Figure 1: Overview of the recursive-dynamic modelling framework G-RDEM

The process typically requires some exogenous projections for GDP and population. The method of endogenizing naturally exogenous variables (such as factor productivity) in baseline construction and then exogenizing in counterfactural analysis has been widely used in most recursive CGE models, like MONASH (Dixon and Rimmer, 2002), LINKAGE (van der Mensbrugghe, 2005), USAGE (Dixon, Koopman and Rimmer, 2013), and many others. G-RDEM offers the possibility to directly draw from a set of projections for the so-called SSPs (Shared Socio Economic Pathways) (Riahi et al., 2016), available online from the IIASA SSPs Database, ${ }^{2}$ and provided with the model code in a ready-to-use format. These SSPs were developed in the context of the IPCC scientific assessment on Climate Change. For each of these five SSPs, a single population and urbanization scenario, jointly developed by IIASA and NCAR (National Center for Atmospheric Research), can be combined with GDP projections from either the OECD or IIASA. These GDP and population projections are available in 5-year steps up to 2100 at the country level. They are aggregated in G-RDEM to the desired regional aggregation and interpolated, to yield yearly time series. They can also be complemented by climate change impacts on yields for a set of Representative Concentration Pathways (RCPs) and various combinations of Global Circulation Models (GCMs) and global gridded crop growth models provided by the AgCLIM50 project (van Meijl et al., 2017).

${ }^{2}$ See https://tntcat.iiasa.ac.at/SspDb/dsd?Action=htmlpage\&page=about 
A user might also add its own scenario assumptions during the construction of the baseline, such as about trade policies or alternative GDP projections. After the definition of the baseline, the software saves the resulting productivity shifters and other variables, which can subsequently be loaded as exogenous parameters for a counterfactual analysis. The results for one time point of the baseline can also be used as a benchmark for comparative-static analysis.

\section{Non-linear Engel curves: An AIDADS demand system with detail for food consumption}

\subsection{Background}

It is universally acknowledged that the relationship between consumption level and income (also known as Engel curve) can be complex and non-linear. Yet, many CGE models still adopt demand systems such as Cobb-Douglas (CD) or Linear Expenditure System (LES), having linear Engel curves. Those simplifying assumptions make the model easier to handle, but are defendable only if the model is used for simulations involving limited changes in income levels. Of course, this is not the case for long-term analyses. Keeping constant marginal budget shares would lead to an overestimation of the demand for necessities, such as food, while demand in other sectors will hence be underestimated. The consequences are implausible long-run structural changes in production, demand, and trade patterns. Some models employed for long-term analysis therefore use different demand systems and/or re-parameterize along the dynamic path. For instance, MAGNET (Woltjer et al. 2014, p. 84) incorporates a module for re-calibrating the parameters of a CDE (Constant Differences in Elasticity) demand system to given income elasticities. Nonetheless, the authors admit: "All of these parameters and functional forms are very much ad hoc, and should be improved."

Following Roson and van der Mensbrugghe (2018), we rather implement an empirically estimated AIDADS demand system into the G-RDEM model, for broad product groups and with some more detail for food, where income effects are especially relevant. The AIDADS is An Implicit, Directly Additive Demand System (Rimmer and Powell, 1996). It can be understood as a generalization of a LES demand system, where marginal budget shares are not fixed, but are a linear combination of two vectors, depicting the marginal budget structure at very low and very high utility (income) levels. Given that the marginal budget shares in the two vectors fulfil the adding up condition to unity, any linear combination of the two vectors also leads to regular budget shares.

Cranfield et al. (2000) improve on the original Rimmer and Powell (1996) approach, by developing an estimation method that does not rely on an approximation of utility. We follow their notation in the following. The demand system is defined below. Equation (1) determines the Marshallian demand, which is identical to that of a LES with the exception that the marginal budget shares $\delta_{i}$ 
are not fixed. The bars indicate econometrically estimated parameters fixed during simulation. Thus, the marginal budget shares $\delta_{i}$ are endogenous variables, defined by (2), expressed as a linear combination of two vectors $\alpha$ and $\beta$, function of the utility level $u$, implicitly defined by (3). $\alpha$ can be interpreted as the marginal budget share at minimum utility level, i.e. very low per capita income, while $\beta$ is the share at very high incomes. $\gamma$ are the constant terms, typically termed commitments. The multiplier $o$ allows for a different impact of changes in utility on the two boundary vectors. The Equation (3) defines the log utility from the consumption bundle where $\bar{\kappa}$ is a constant term.

$$
\begin{gathered}
x_{i}=\gamma_{i}+\frac{\delta_{i}}{p_{i}}\left[Y-\sum_{j} \gamma_{j} p_{j}\right] \\
\delta_{i}=\frac{\bar{\alpha}_{i}+\bar{\beta}_{i} o u}{1+o u} \\
\ln (u)=\sum_{i} \delta_{i} \ln \left(x_{i}-\gamma_{i}\right)+\bar{\kappa}
\end{gathered}
$$

\subsection{Estimation}

We follow closely Cranfield et al. (2000) in our estimation, i.e. by performing a log-likelihood estimation on panel data, referring to the year 2011, from the ICP International Comparison Program, which provides a harmonized data set on expenditures, consumer prices and purchasing power parities. Deriving confidence intervals for the estimated coefficients requires a numerically quite expensive bootstrapping procedure. As the results would not impact the simulation behavior of the model (where the estimates mode is used), we calculate only the explained variance, as shown in Table 1. 
Table 1: Estimated coefficients and fit

\begin{tabular}{|c|c|c|c|c|}
\hline & Alpha & Beta & Gamma & $\mathrm{R}^{2}(\%)$ \\
\hline Clothing and footwear & $5,43 \%$ & $3,62 \%$ & 0,00 & 12 \\
\hline $\begin{array}{l}\text { Housing, water, } \\
\text { electricity, gas and other } \\
\text { fuels }\end{array}$ & $7,33 \%$ & $22,89 \%$ & 10,26 & 39 \\
\hline $\begin{array}{l}\text { Furnishings, household } \\
\text { equipment } \\
\text { and maintenance }\end{array}$ & $6,09 \%$ & $4,24 \%$ & 37,72 & 2 \\
\hline Health & $3,94 \%$ & $11,14 \%$ & 7,70 & 55 \\
\hline Transport & $8,54 \%$ & $11,76 \%$ & 20,33 & 26 \\
\hline Communication & $2,75 \%$ & $3,54 \%$ & 38,99 & 11 \\
\hline Recreation and culture & $0,00 \%$ & $8,70 \%$ & 0,82 & 74 \\
\hline Education & $6,70 \%$ & $7,88 \%$ & 1,26 & 10 \\
\hline Restaurants and hotels & $1,32 \%$ & $7,62 \%$ & 11,53 & 34 \\
\hline $\begin{array}{l}\text { Miscellaneous goods and } \\
\text { services }\end{array}$ & $1,27 \%$ & $14,36 \%$ & 0,30 & 71 \\
\hline Cereals & $12,96 \%$ & $-1,54 \%$ & 2,65 & 76 \\
\hline Oils & $2,41 \%$ & $-0,29 \%$ & 0,00 & 62 \\
\hline Fruit & $2,80 \%$ & $0,60 \%$ & 0,00 & 38 \\
\hline Vege & $8,77 \%$ & $-0,86 \%$ & 0,00 & 60 \\
\hline Sweets & $2,60 \%$ & $0,35 \%$ & 0,47 & 44 \\
\hline Fish & $4,51 \%$ & $-0,39 \%$ & 0,00 & 40 \\
\hline Meat & $9,19 \%$ & $1,22 \%$ & 5,30 & 45 \\
\hline Dairy & $4,43 \%$ & $1,23 \%$ & 9,38 & 32 \\
\hline Eggs & $0,93 \%$ & $0,10 \%$ & 0,00 & 34 \\
\hline Coffee, Teas, Cocoa & $0,77 \%$ & $0,25 \%$ & 0,00 & 22 \\
\hline Soft drinks & $1,70 \%$ & $0,79 \%$ & 0,00 & 12 \\
\hline Alcoholic drinks & $1,72 \%$ & $1,37 \%$ & 0,00 & 10 \\
\hline All other food & $3,86 \%$ & $1,43 \%$ & 0,00 & 26 \\
\hline
\end{tabular}

Source: Own estimation.

Table 1 reports the estimated coefficients and the fit for the different categories. Quantities during the estimation are expressed in USD dollars and corrected for differences in prices. The $\gamma$ commitment terms are all quite low when considering that income reaches up to around 50,000 USD in the sample. The fit differs considerably among categories. A measure of fit over $60 \%$ is achieved for "Recreation and culture", "Miscellaneous goods and services" and several food categories (cereals, oils, vegetables). Then, there is group with a more moderate fit around $40 \%$ to $60 \%$, including "Housing and related expenditures", "Health", "Fruits", "Sweets", "Fish" and "Meat". For the remaining categories, the income 
dependence appears as weak and might be overshadowed by cultural habits, such as in the case of alcohol. That might also explain why the category of mineral waters and soft drinks has a low fit.

Generally, the reader should keep in mind the difference between expenditure levels and budget shares. Let us take education as an example: the expenditure at low income levels (500 USD) is $6.7 \%$ plus the 1.26 USD of the constant term, i.e. about thirty dollars. At 50,000 USD, the $8 \%$ will imply an expenditure of 4,000 USD. On the other hand, production costs and prices for educational services are also generally higher in high income countries.

Figure 2 shows the expenditure shares resulting from the AIDADS estimation at mean sample prices, for income levels between 500 and 50,000 USD. At very low income levels, more than one third is dedicated to food (38\%), around $20 \%$ is given to housing and $7 \%$ to transport, $5 \%$ to Furnishing, household equipment and maintenance. As one can notice also from Table 1, budget shares for education actually drop, the shared decreases from somewhat below $9 \%$ at low income levels to around $5 \%$ at higher income level. However, as already noticed, actual expenditure levels would nonetheless be much higher.

At very high expenditure levels, the share for food drops to about 15\% while shares for housing decrease slightly to around $18 \%$. Shares for health care are almost doubling, reaching $10 \%$, whereas for restaurants and hotels they increase by a factor five, up to $8 \%$. A similar large increment is observed for the residual category "Miscellaneous goods and services", from $4 \%$ to $13 \%$, and for "Recreation and culture" growing from less than $2 \%$ to around $8.5 \%$. 


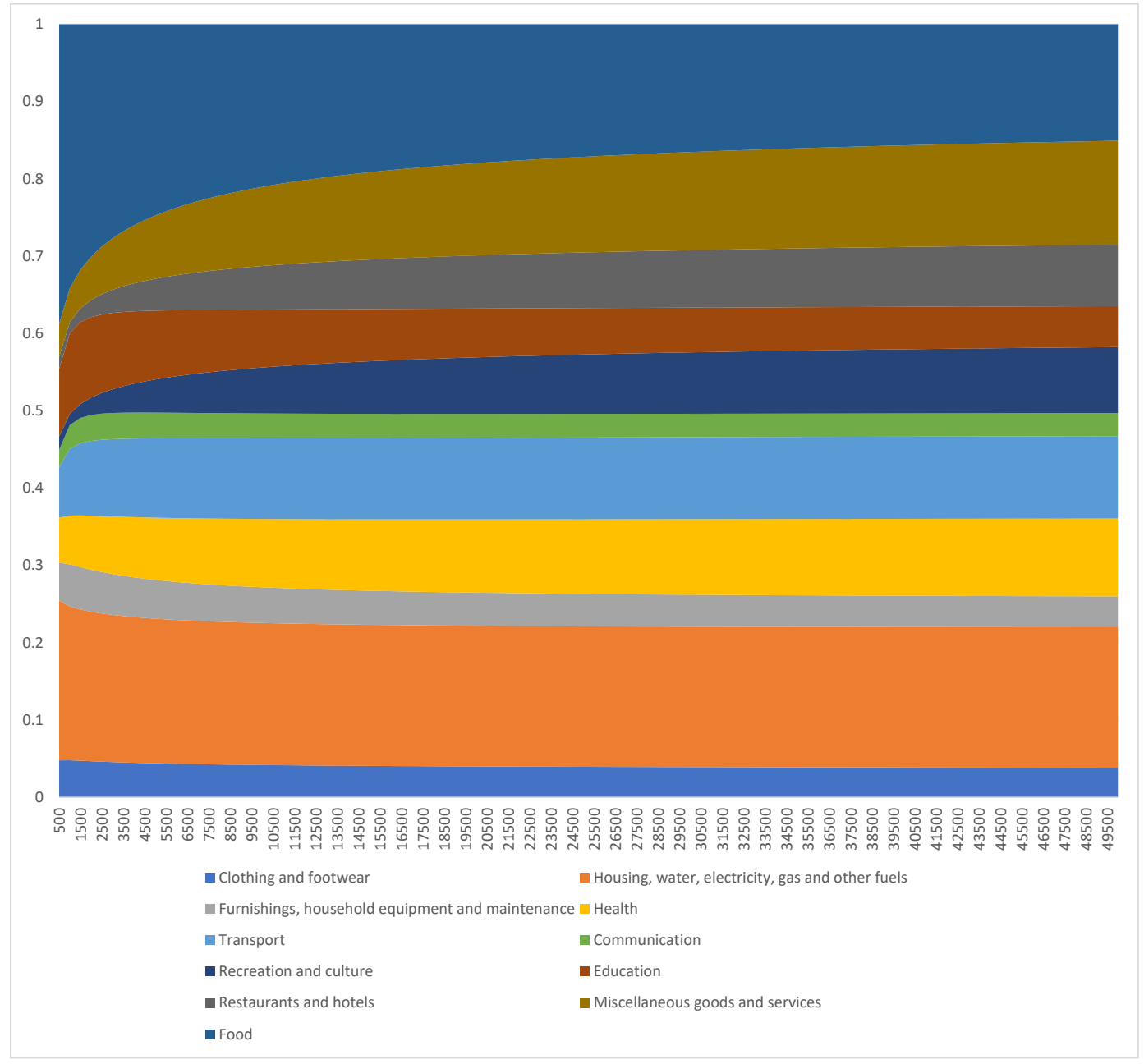

Figure 2: Expenditure shares simulated at sample mean prices, AIDADS

Source: Author calculations.

Figure 3 below provides more detail for food categories in the AIDADS system. It reports shares on total food expenditure. At very low income levels, cereals have the highest shares with around 33\%. Perhaps astonishing, meat follows with $12 \%$. However, the aggregate of crop based products (cereals, vegetable oils, fruits and vegetables) accounts for almost half of the non-committed food expenditure. At high income levels, the share of cereal derived products drops to less than $10 \%$. Perhaps surprisingly, there is a large drop from $12 \%$ to $8 \%$ for vegetables, which mostly reflects the importance of vegetables like roots and tubers (Yams, Cassava etc.) as staple food. Relatively stable are the shares for sugar and sweets, which increase from around $3 \%$ to around $6 \%$ and fruits, which increase slightly from $4 \%$ to $7 \%$. Increases in the shares are observed for animal products, with meat 
increasing from $12 \%$ to $16 \%$, dairy from $5 \%$ to $12 \%$, and, more modestly, eggs from $1.1 \%$ to $1.5 \%$. Similarly, the fish share increases from 5 to $6 \%$. The highest increases are found for soft drinks (including mineral water), from $2 \%$ to $6 \%$, and alcohol, from $5 \%$ to $12 \%$. These compositional changes interact with the discussed overall drop in the expenditure share for food if total per capita expenditure increase.

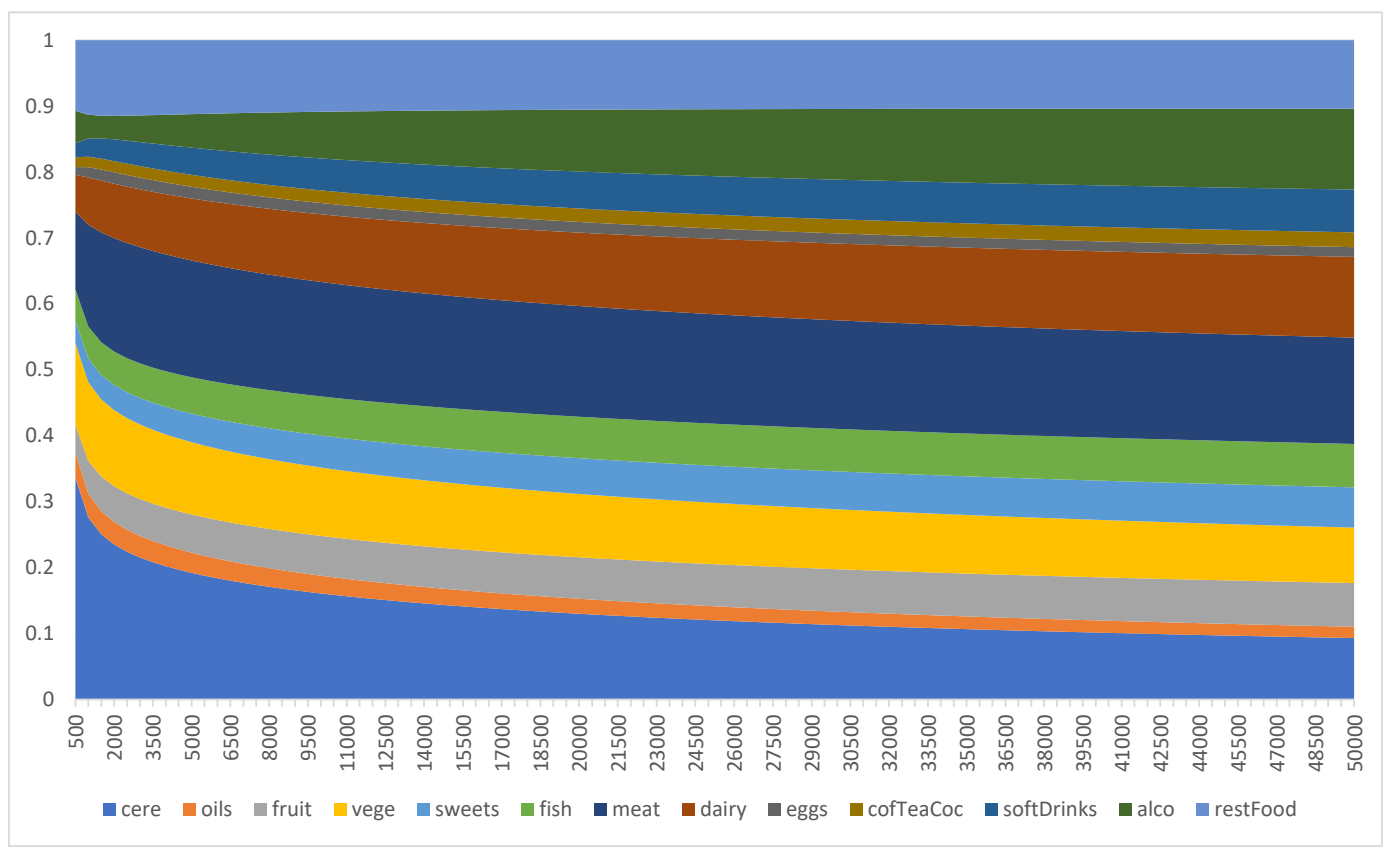

Figure 3: Expenditure shares for food categories at mean sample prices

Source: Author calculations.

\subsection{Integration in G-RDEM}

The integration in the CGE model requires mapping the parameter estimates to the commodity resolution of the model (see Annex).

The demand system is calibrated against the benchmark data of regional household consumption, from the GTAP Data Base Version 93. To this purpose, we regressed the utility levels $u$ from our findings to the log of per capita consumption expenditure $Y$ in each region, linear and quadratic. The $\mathrm{R}^{2}$ fit is quite high (94\%). The relationship allows us to estimate (from (2)) the marginal budget shares $\delta_{i}$ at the calibration point. We then discarded the previously estimated $\gamma$ and instead solve (1) for $\gamma$ at given $x, Y, p$ and the calibrated marginal budget shares. In the case that this implies a negative $\gamma$, we use a penalty minimization

${ }^{3}$ Details on the implementation in the actual model code for all the elements discussed in this and subsequent sections are provided as supplementary material. 
approach, which minimizes the difference between the estimated $\alpha, \beta$ and the "corrected" ones, such that all $\gamma s$ turn out to be positive.

\section{Differentiated productivity growth}

\subsection{Background and literature review}

Productivity does not vary uniformly among industries and sectors. Harberger (1998) points out that the whole dynamics of economic progress actually resembles the erratic and unpredictable growth process of "mushrooms", rather than the steady and homogenous rise of "yeast". Indeed, differential productivity growth is one key factor of structural change in the economic systems, and probably the most important one (Swiecki, 2017). Several implications of different growth rates have been investigated in the literature, e.g.: relevance and empirics of the socalled "Baumol's disease" (Baumol 1986; Triplett and Bosworth 2003; Young 2014); specialization and international trade (McMillan and Rodrik, 2011; Caron and Markusen, 2014); "premature deindustrialization" (Rodrik, 2016).

To introduce differentiated productivity growth in the G-RDEM model, we build on Roson (2019), who estimated trends in labour productivity, using the Groeningen GGDC 10-Sector Database (de Vries et al., 2015). In that study, some trends and country specific dummies for labor productivity (VA/employment) are estimated. Results are subsequently employed in a cluster analysis, where three groups of countries with similar characteristics are identified.

Table 2 below shows some of the findings used to obtain parameters for GRDEM, to be interpreted as follows. A cluster of fast-growing countries is identified, and for them the average grow th rate in labor productivity is computed to be $8 \%$ per year. It refers to value added per worker or hour, so it accounts for capital deepening and similar effects. This national growth rate is actually the weighted aggregation of sectoral rates: $6.23 \%$ in Agriculture, $11.43 \%$ in Manufacturing and $5.65 \%$ in the Services. A similar interpretation applies to the other two clusters.

Table 2: Average labour productivity growth rates

\begin{tabular}{l|llll} 
Cluster & Agriculture & Manufacturing & Services & Total \\
\hline Rising & 6.23 & 11.43 & 5.65 & 8 \\
Steady & 7 & 7.88 & 5 & 5.93 \\
Lagging & 5.17 & 5.32 & 2.34 & 3.16 \\
Source: Roson, 2019 & & &
\end{tabular}

Notice that, as one could expect, Services are always the slowest sector, but the relative distance between Services and the other two sectors varies with the level of overall growth. This suggests that, instead of assuming a fixed hierarchy of productivity increments (e.g., Agriculture two times larger than in the Services, Manufacturing three times), the growth gap would be better expressed as a 
function of, for instance, the percentage change in the GDP. This is indeed what the G-RDEM model does.

Relative differentials in productivity between sectors depends on the overall grow th rate of the economy because of the different role the sectors play at various stages of economic development. It is a stylized fact that fast-growing, developing countries are typically associated with intense industrialization, where manufacturing is key (Haraguchi et al., 2017).

\subsection{Estimation}

In the G-RDEM model we are not concerned about labor productivity in itself, but rather on the relative differences among the three broad sectors of Agriculture, Manufacturing and Services. To this end, a correspondence between the three clusters and the annual GDP growth rates used in the SSPs was established. The distribution of IIASA SSP data (OECD) on GDP was considered, and it was assumed that the average GDP growth in the Lagging group of countries corresponds to the $20 \%$ percentile of the SSP distribution, $50 \%$ for Steady, $80 \%$ for Rising. This means $1.2 \%, 2.5 \%$, and $4.9 \%$, respectively.

Second, the ratio of each sector productivity rate, relative the slowest growing sector, which is Services, was computed. Third, for each industry a quadratic interpolation between the three multipliers and the references GDP growth rates was undertaken, thereby getting three parameters of a quadratic relationship between a sectoral productivity shifter (ratio between industry growth rate and the corresponding one in the Services) and GDP annual growth.

This gives raise to the functions displayed in Figure 4 which should be interpreted as follows. On the horizontal axis, we consider different levels of national, aggregate GDP growth. The grey line is the relative productivity in the Services, which is always one because of normalization. The orange and blue curves are the relative TFP growth rates in Manufacturing and Agriculture, respectively.

It is found that productivity differentials are smallest (although still significant) at a moderate GDP growth of around $2 \%$, where the three functions are closest. For higher or lower rates, we can see that the differences amplify, with manufacturing becoming the key sector. Notice that the shifter is a multiplier: if aggregate growth is negative, all sectors will also show negative growth rates. In that case, when the shifter for Manufacturing is high productivity is decreasing there more than in the rest of the economy. In other words, productivity growth in Manufacturing appears as strongly correlated with the aggregate productivity growth, which suggests the existence of inter-sectoral externalities. 


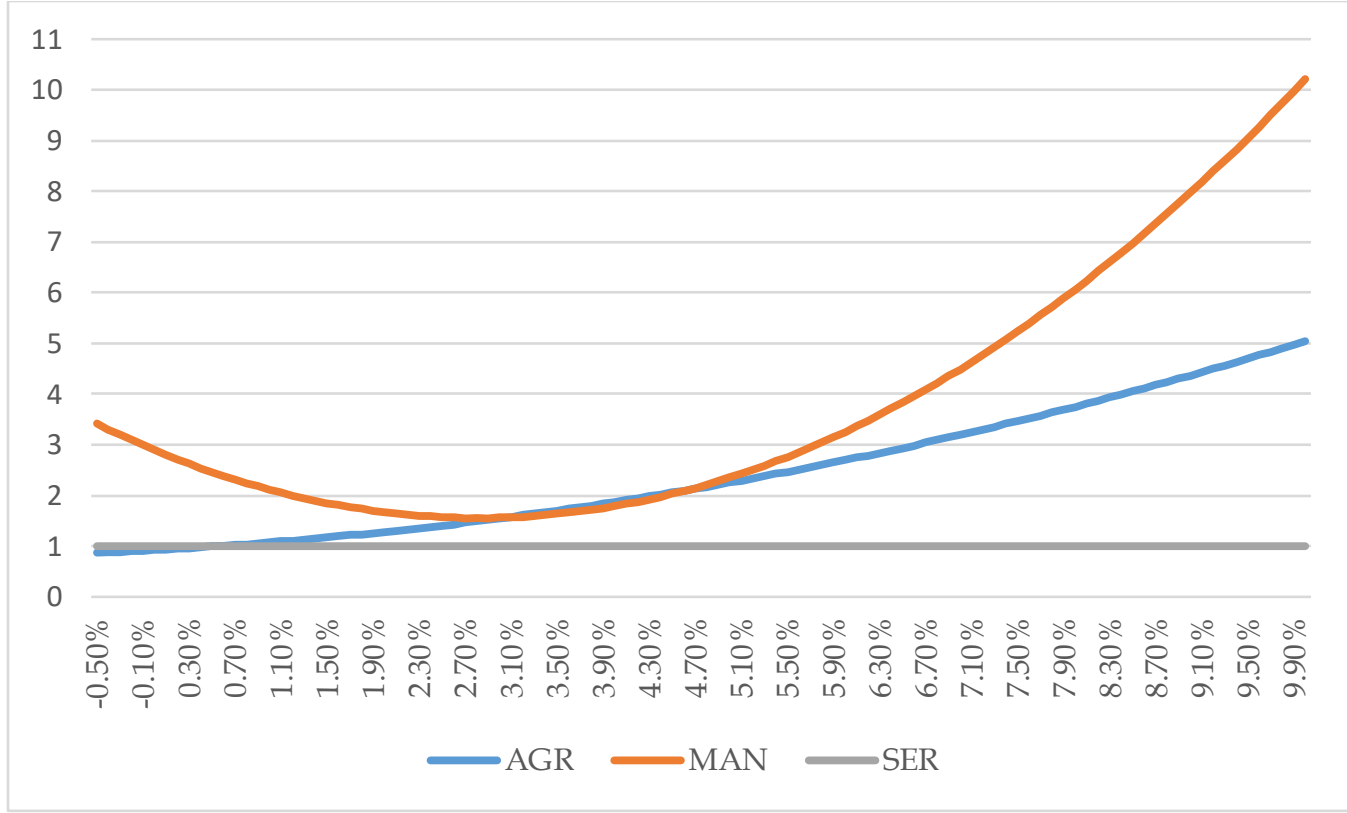

Figure 4 : Productivity growth relative to GDP growth

Source: Author calculations.

Implementation in G-RDEM is quite straightforward. Total factor productivity in the Services $t f p(r)$ becomes endogenous during the construction of the baseline, when national GDP is taken as given. The computed level of total factor productity in the Services gets back to exogenous during counterfactual simulations, whereas productivity for other sectors is always obtained as relative to the one in the Services, depending on the overall GDP growth. More precisely, TFP for sectors other than Service (indexed by $i$ ) in region $r$ at time $t+1$ are defined as $t f p(r){ }^{*} \operatorname{sh}(i, r)$, where the latter is determined by a quadratic relationship with GDP growth rates:

$$
\begin{gathered}
S h(i, r)=a+b \frac{g d p(r, t+1)-g d p(r, t)}{g d p(r, t)} \\
+c\left(\frac{g d p(r, t+1)-g d p(r, t)}{g d p(r, t)}\right)^{2}
\end{gathered}
$$

\footnotetext{
${ }^{4}$ Technically, a "swap" between normally endogenous GDP and normally exogenous total factor productivity (in the Services). Productivity in the rest of the economy is always endogenous and determined by equations like (4).
} 
Here are the estimated values for the three parameters $a, b$ and $c^{5}$ :

Table 3: Estimated parameters for sector specific productivity growth

\begin{tabular}{c|ll} 
& Agriculture & Manufacturing \\
\hline a & 0.925391 & 2.893917 \\
b & 11.99205 & -94.8599 \\
c & 291.8147 & 1680.554 \\
\multicolumn{2}{l}{ Source: Author calculation`s. }
\end{tabular}

\section{Endogenous saving rates}

\subsection{Background and literature review}

We aim at developing a simple but robust mechanism to render aggregate saving rates in G-RDEM endogenous. One strand of literature, relying on crosscountry differences of saving rates (e.g. Kisanova and Sefton, 2007), works with micro-economic survey data. It explicitly accounts for factors such as demography, welfare state, retirement behaviour, borrowing constraints, income distribution over a lifetime and its uncertainty, as well as capital gains. The focus here is on the life-cycle hypothesis, which considers the change in available income over a lifetime. While these papers give robust evidence that the factors indeed explain the saving behaviour of individuals or households, they typically offer results only for one or a smaller group of countries.

Rather, we draw here on studies which employ cross-sectional analyses over countries to evaluate the factors affecting the economy-wide aggregate saving rates. Most of these works also take the lifecycle hypotheses into account (although indirectly) and find that even in cross-country analyses larger proportions of the young and the elderly compared to persons in working age (dependency ratios) generally decrease the saving rate (Doshi, 1994; Masson et al., 1998; Laoayza et al., 2000).

\subsection{Estimation}

Instead of directly using parameter values from the literature, we carry out our own cross-section estimation, using GTAP Data Base Version 9 and other data used in our modelling framework, to overcome any potential divergence in definitions, measurement units, etc. The reader might note that we face a potential endogeneity issue: higher rates of GDP growth require increased capital accumulation, thus larger net investments and consequently higher saving rates. The saving rate and GDP growth are hence structurally dependent. However, this is not an issue in our estimation, as we are not using the realized growth rate from 2010 to 2011, the latter the observation year for the dependent variable, but an average GDP growth rates from 2010 to 2015.

\footnotetext{
${ }^{5}$ For the Services, $a=1, b=c=0$.
} 
The distribution of the national aggregate saving shares in the GTAP Data Base Version 9 reveals a large spread, as shown in the Figure 5. We regressed those saving rates with OLS against the following explanatory variables:

- Population composition by age group from the IIASA repository for 2010 (Lutz et al., 2017), captured by two variables: the dependency ratio for young persons (up to 14 years relative to 14-65 years) and the dependency ratio for the elderly (above 65 years relative to 14-65 years).

- Average yearly GDP growth per capita from 2010 to 2015, in PPPs, from the OECD Env. Growth Model data base as found in the IIASA repository.

- The trade balance (by construction of the GTAP Data Base equal to foreign savings) relative to regional income, from the GTAP 9 Data Base.

We also tested, as a potential explanatory variable, the share of government consumption on regional income, but did not find a statistically significant relation.

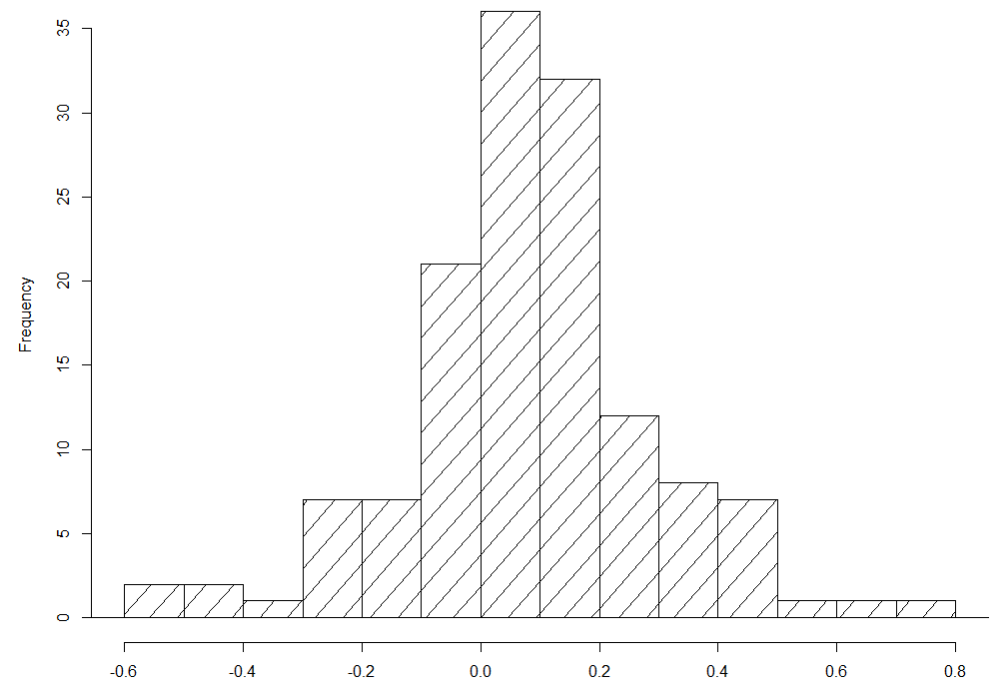

Figure 5 : Distribution of aggregated savings rates in GTAP 9

Source: Author calculations (or appropriate source(s)).

We found a very good fit, with a $\mathrm{R}^{2}$ at $92 \%$ and all variables (with the exemption of the young dependency rate) statistically significant at $<0.1 \%$, see Table 4 . The young dependency ratio is nonetheless significant at the $5 \%$ level. All variables have the expected sign: dependency ratios decrease the saving rates, as postulated by the life cycle hypothesis, while a higher income per capita and a higher growth rate increase the saving rate. A positive trade surplus (i.e. negative foreign savings) also tends to increase the saving rates. 
Table 4: Regression output for saving rate estimation

\begin{tabular}{|l|r|r|r|r|}
\hline Coefficient & \multicolumn{1}{|c|}{ Estimate } & \multicolumn{1}{|c|}{ Std. error } & t-value & $\operatorname{Pr}(>|\mathbf{t}|)$ \\
\hline Intercept & 0.258 & 0.058 & 4.401 & $2.22 \mathrm{e}-05^{* * *}$ \\
\hline Yearly GDP growth \% & 2.208 & 0.390 & 5.659 & $9.18 \mathrm{e}-08^{* * *}$ \\
\hline GDP per capita & 0.001 & 0.0003 & 2.899 & $0.00439^{* *}$ \\
\hline $\begin{array}{l}\text { Dependency ratio } \\
\text { elderly, square root }\end{array}$ & -0.364 & 0.079 & -4.590 & $1.02 \mathrm{e}-05^{* * *}$ \\
\hline $\begin{array}{l}\text { Dependency ratio } \\
\text { young persons, } \\
\text { square root }\end{array}$ & -0.145 & 0.056 & -2.583 & $0.01089^{*}$ \\
\hline $\begin{array}{l}\text { Trade balance, relative } \\
\text { to regional income }\end{array}$ & -0.967 & 0.047 & -20.433 & $<2 \mathrm{e}-16^{* * *}$ \\
\hline $\begin{array}{l}\text { Trade balance, relative } \\
\text { to regional income, } \\
\text { squared }\end{array}$ & 0.334 & 0.067 & 4.944 & $2.30 \mathrm{e}-06^{* * *}$ \\
\hline
\end{tabular}

Notes: Signif. codes: $0^{\star * * * \prime} 0.001^{\star * * \prime} 0.01^{\star * \prime} 0.05$. Residual standard error: 0.05893 on 131 degrees of freedom. Multiple R-squared: 0.9213, Adjusted R-squared: 0.9177. F-statistic: 255.5 on 6 and 131 DF, p-value: $<2.2 \mathrm{e}-16$

Source: Author calculation`s.

The good fit of the regression stems to a large degree from the inclusion of the trade surplus relative to regional income, (see Table 5 below), while the far smaller contributions of the dependency ratios and GDP per capita are in a similar range, with GDP growth trailing.

Table 5: Analysis of Variance for saving rate estimation

\begin{tabular}{|l|r|r|r|r|}
\hline Coefficient & \multicolumn{1}{|c|}{ DF } & \multicolumn{1}{c|}{ Sum Sq } & F value & $\operatorname{Pr}(>|\mathbf{t}|)$ \\
\hline Yearly GDP growth \% (GDPGrowthRate) & 1 & 0.0001 & 0.0287 & 0.8658 \\
\hline GDP per capita (GDPPerCap) & 1 & 0.5271 & 151 & $<2.2 \mathrm{e}-16^{* * *}$ \\
\hline $\begin{array}{l}\text { Dependency ratio } \\
\text { elderly, square root (SqrtDepRateEldery) }\end{array}$ & 1 & 0.5092 & 146 & $<2.2 \mathrm{e}-16^{* * *}$ \\
\hline $\begin{array}{l}\text { Dependency ratio young persons, } \\
\text { square root (SqrtDepRateYoung) }\end{array}$ & 1 & 0.3712 & 106 & $<2.2 \mathrm{e}-16^{* * * *}$ \\
\hline $\begin{array}{l}\text { Trade balance, relative to regional income } \\
\text { (BotToRegy) }\end{array}$ & 1 & 3.8306 & 1103 & $<2.2 \mathrm{e}-16^{* * * * *}$ \\
\hline $\begin{array}{l}\text { Trade balance, relative to regional } \\
\text { income, squared }\end{array}$ & 1 & 0.0849 & 24 & $2.297 \mathrm{e}-06^{* * *}$ \\
\hline Error term & 131 & 0.4549 & & \\
\hline Souce: Aun car & & & & \\
\hline
\end{tabular}

Source: Author calculation`s.

Scatter plots (visualizing the ANOVA results above) between the explanatory variables and the saving rate are shown below in Figure 6. It shows the strong relation between the trade surplus and domestic savings in the GTAP data base. 

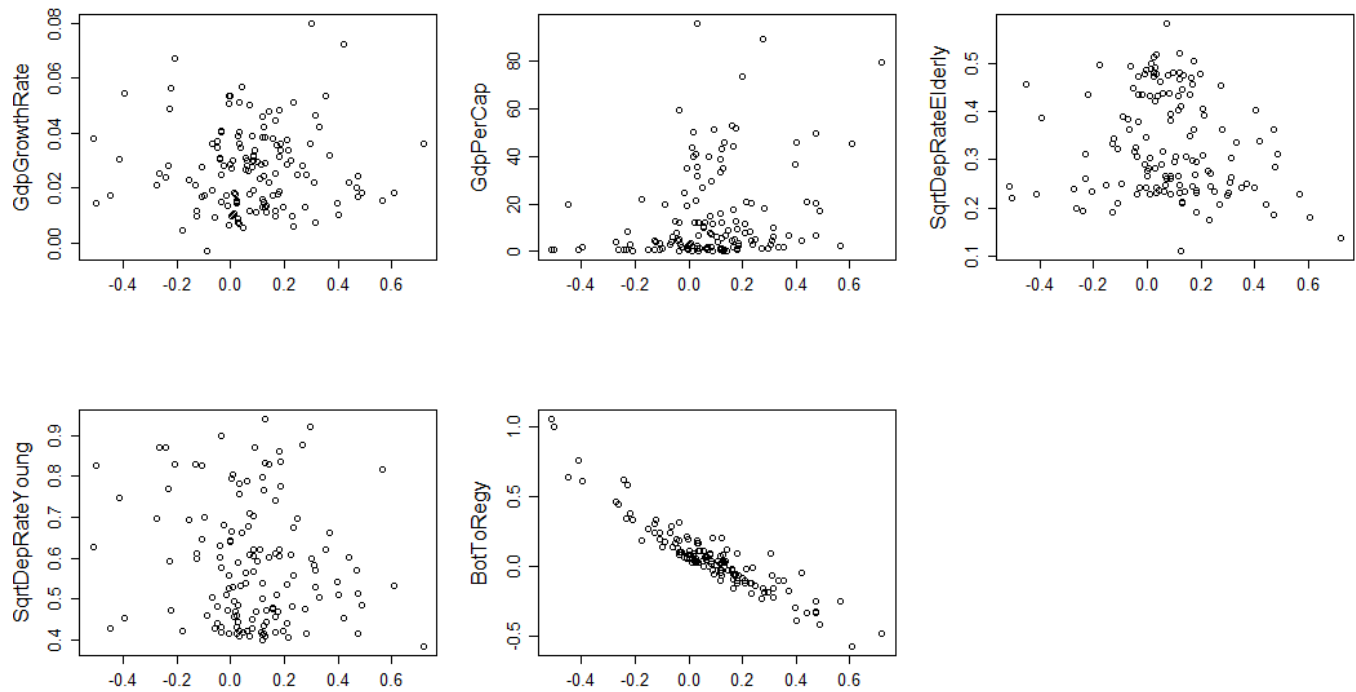

Figure 6 : Scatter plots of explanatory variables against the saving rate

Note: Descriptions of labels can be found in table 5 above.

Source: Author calculations.

In order to shed further light on the contribution of the trade surplus, the scatterplot for the fitter versus observed (Figure 8 below) adds labels for the regions with the largest and lowest domestic savings rates in the GTAP Data Base. Countries with high saving rates seems to be mainly exporters of fossil resources and minerals (qat for quatar, kwt for Kuwait and xcf, i.e. rest of Central Africa which comprise as the largest country Congo as an exporter of oil, diamonds and gold). We tried therefore also to include indicators such as the factor income from extraction sectors relative to regional income or export revenues from extraction sectors relative to regional income in the regression, but did found any improvement in the explained variance while the other regression coefficients were relatively stable. Very low saving rates are often found for some developing countries (ben for Benin, tgo for Togo), but also for mlt (Malta) which in 2011 was still in the aftermath of the economic crisis as well as for kgz (Kyrgyzstan) and XEE (Modova) as former Soviet Union Republics with structural trade deficits and large inflow of remittances). Thus, the trade surplus indicator might be partly interpreted as a kind of control variable for country specific unobserved features (large receiver of development aid in a group a country with otherwise similar macro-economic indicators, rich oil and gas reserves, tax havens ...). 


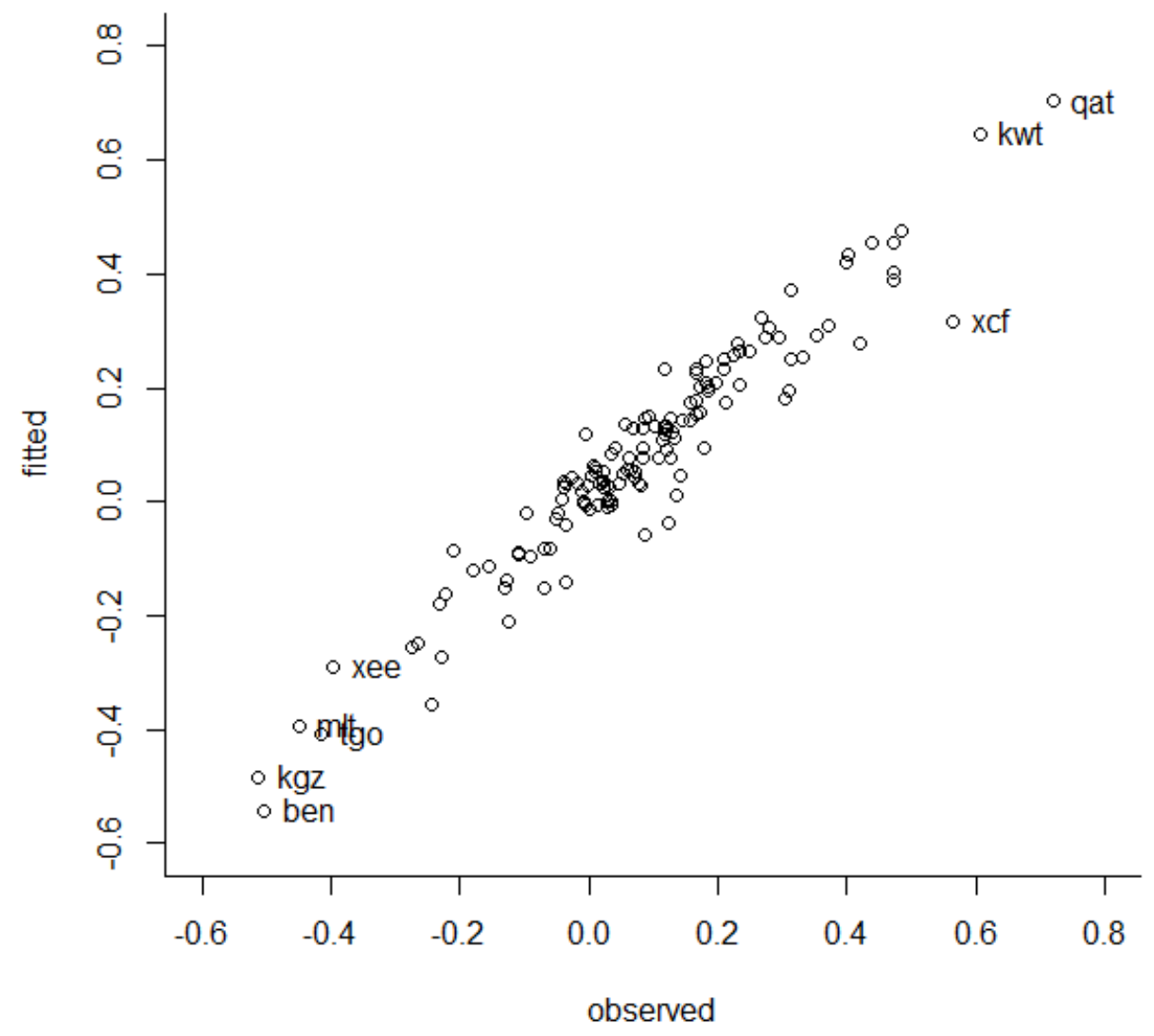

Figure 7 : Fitted against observed saving rates

Note: GTAP region codes as labels added for savings rates outside of the median plus/minus 2.5 times the inner quartile range.

Source: Author calculations.

The foreign savings is the only element of the balance of payment found in the GTAP Data Base and hence by definition equal to the trade deficit. Debt servings and other elements of the balance of payments are not accounted for. The sum of foreign and domestic savings is by definition equal to total investment. Some correction to these positions (trade balance, foreign savings, domestic savings, and investments) must occur to correct for missing elements in the balance of payments. We cannot exclude that the large contribution of the trade balance in explaining domestic savings rates also reflects data construction. Indeed, if the observations are restricted to the inner quartile range of the domestic saving rate, 
excluding the $25 \%$ lowest and highest observations, the explanatory power of the trade surplus is about halved along with its regression coefficient.

To exclude potential bias in the dependent variable from data construction, other data on domestic saving rates could be used instead. If differences between the GTAP Data Base and such an alternative data set are however systematic, using the resulting regression coefficients to update saving rates in G-RDEM stemming from the GTAP Data Base is also doubtful.

These points let us cautiously exclude changes in the trade surplus when updating savings rates during the process of baseline construction. Furthermore, the fitted values cannot be used as such. The error term in the regression might imply large changes in the saving rates from the benchmark to subsequent simulation periods in some countries. Instead, we use relative changes in the estimates - neglecting the trade balance - to update the saving rates used in the model. Details of the implementation are further discussed in the Technical Annex.

\section{Debt accumulation from foreign savings}

Accounting identities in the model ensure (for each time period) that the sum of regional and foreign savings in each region equals gross investments, while, in the GTAP Data Base and standard model, foreign savings are equal to the foreign trade deficit. The latter is determined, in the GTAP model (Hertel and Tsigas, 1997; Corong et al., 2017), which defines the intra-period equilibrium in G-RDEM) by the so-called global bank mechanism which steers the regional allocation of investments, as already found in the ORANI model for Australia (Dixon et al., 1982). This is based on a distribution of global savings, driven by relative expected returns on capital, as it is briefly illustrated in the following (equations 5-8) as it forms the basis for the subsequent expansion, even if it is part of the GTAP standard model.

Let denote the price of a homogeneous capital factor (services) as $p_{c}$ and $p_{i}$ as the price of investments (the cost of producing one unit of new capital good), $\kappa$ the tax rate on capital earnings, fdepr the depreciation rate. The net rate of return in a region $r$ (rorc) is defined in the GTAP model as:

$$
\operatorname{rorc}_{r}=\frac{p_{c, r}\left[1-\overline{\kappa_{r}}\right]}{p_{i, r}}-\overline{f d e p r}
$$

The expected rate of return rore takes into account the difference between start and end of period capital stocks, $k_{s}$ and $k_{e}$. The logic is that investors should become more cautious when aggregate investments lead to large changes in capital stocks: 


$$
\text { rore }_{r}=\operatorname{rorc}_{r}\left(\frac{k_{s, r}}{\overline{k_{e, r}}}\right)^{\overline{\text { rorFlex }}}
$$

The parameter rorFlex (whose default value is 10 for all for regions) dampens the relative differences in expected returns, thereby avoiding the generation of unrealistically large flows of (real) capital in international markets. In addition, a regional risk factor is introduced, to ensure that an arbitrage condition for the international investor holds in the calibration data set, meaning that a single global, risk-adjusted return rorg is identified:

$$
\text { rore }_{r} \overline{\text { risk }_{r}}=\text { rorg }
$$

The condition (7) holds in all periods in G-RDEM, where rorg and rore are endogenous variables. Therefore, the relationships above drive the distribution of foreign savings $f s a v$ or, equivalently, the amount of investments in each region (which do not generally match with regional savings).

The global investor hence expects equal returns of rorg on his savings in any region. Accordingly, the returns in year $t$ from foreign savings add up to zero as, by construction, the global economy is closed, and total investments equal total savings (equivalently, the global trade balance is zero):

$$
\sum_{r} f_{s a v_{r}} \equiv 0
$$

In its multi-periodal setting, G-RDEM considers the dynamics of foreign debts accumulation. To this end, we assume that regions, which had received foreign savings $\left(f_{s a v}>0\right)$ in previous years $t t$, will pay in the current year $t$ the expected returns to their foreign debtors, while investing regions $(f s a v<0)$ will be paid back:

$$
\text { captrans }_{r, t}=\sum_{t t<t} f_{s a v_{r, t t}} \text { rorg }_{t}
$$

These payments on the stock of foreign debt captrans enter the equation defining the regional income regy, in addition to the factor income facty and the indirect tax income $y$ TaxInd,

$$
\text { regy } y_{r, t}=\text { fact }_{r, t}+y \text { TaxInd }_{r, t}-\text { captrans }_{r, t}
$$

Note the stock of foreign debt in the first simulation year is assumed to be zero.

The GDyn (Ianchovichina and McDougall, 2010) model shares some similarities with our debt accumulation mechanism. Similar to us, an international trust allocates international investment flows (pool type), thereby avoiding bilateral flows. However, different from us, interest rates differ and debt stock is implicit in the stock of assets assigned to the various owners over time.

A practical issue emerged when the mechanism above was applied to some special cases, where foreign savings account for a large share of investments or total final consumption. Examples are some developing countries, receiving large amounts of development aid or remittances, but also "tax havens" such as Malta. In such cases, we noticed that the mechanism above could lead, after some periods, 
to a situation where regional income gets unrealistically small. To avoid such extreme cases, while allowing for the existence of capital inflows or outflows determined by factors other than expected returns, we introduced a regional share parameter, such that only part of the debt may actually be served (see the Technical Annex for more details).

\section{Cost-share adjustment}

\subsection{Intermediate inputs composite}

To what degree the cost share of total intermediate demand on total output value changes in the course of economic development is an empirical question, whose answer depends on many factors, such as the industrial composition, the price structure, etc.. Analogously, cost shares might be subject to change for individual sectors.

We therefore use again the GTAP Data Base Version 9 for a statistical analysis, taking from there data on cost shares for the intermediate composite in the 57 GTAP industries and regional GDP per capita. We exclude values which were 2.5 times the inter-quartile range, i.e. between the first and third quartile, away from the median. The estimations were performed on the log of the intermediate costs share relative to the log of income per capita and the square of log income per capita to capture potential saturation effects or turning points:

$$
\log C_{j}^{(k)}=\alpha_{o j}+\alpha_{1 j} \log Y P C^{(k)}+\alpha_{2 j}\left(\log Y P C^{(k)}\right)^{2}
$$

where $C_{j}^{(k)}$ is the share of intermediates in the costs of industry j in region k. We used a model selection procedure to remove insignificant coefficients. Population acted as regression weights to avoid that smaller countries with similar income levels, such as e.g. in case of the EU27 or partly for Africa, carry too much weight.

We find that the link between GDP per capita and the intermediate cost share can be generally confirmed (see Figure 8 ). However, for nine industries, the model selection process dropped the relation altogether while the remaining coefficients are mostly highly significant (see Table 6). 


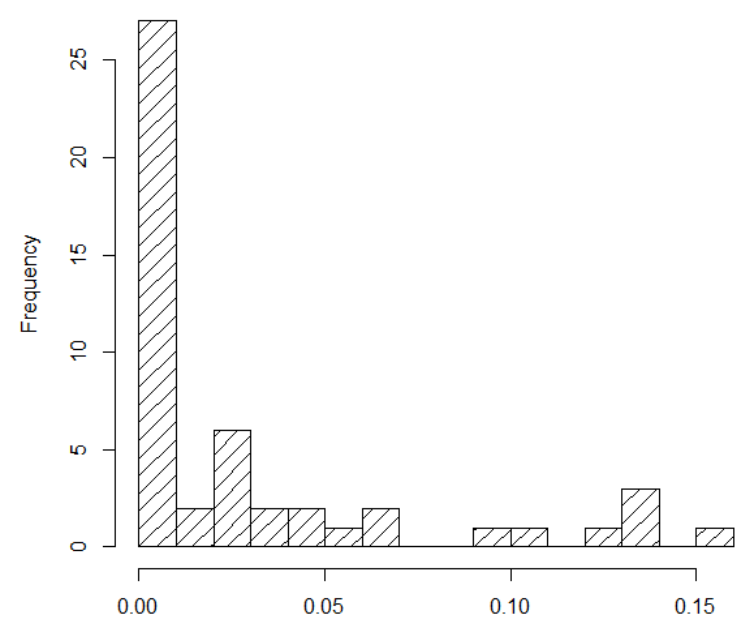

Figure $8: p$-value of regression coefficients of per capita income for cost share of intermediate composite

Source: Author calculation`s.

There is however no linear trend connecting economic growth to the share of intermediate costs, see Table $6^{6}$. Our regression reveals that up to around 5,000 USD per capita, the share of intermediate costs in the economy normally increases (first line, "tot", in Table 6). A possible explanation could be the growing share of manufacturing in the economy, where the share of intermediates is higher. At higher income levels, the share drops, possibly reflecting the generally lower cost shares of intermediates in service sectors.

On the other hand, our estimates provide rather clear results for agricultural activities: with the exception of wheat (wht), all agro-industries show increasing cost shares of intermediates at higher levels of per capita income (rows pdr until wol). For animal processes (rows ctl until wol), the differences in the shares are more pronounced compared to crops (row wht until ocr). Similarly, there are strong increases in intermediate shares for forestry (frs), fisheries (fsh) and coal mining (coa), and moderate ones for "other minerals" (omn), whereas the shares are dropping for oil extraction (oil) and no significant relation was found for the gas extraction (gas).

Contrary to primary sectors, almost no manufacturing industry displays increasing shares (rows cmt until omf). Food (ofd) and meat processing (cmt, omt) as well as oil seed crushing (vol) show no clear relation to income. For the remaining food processing sectors (in the rows $\mathrm{cmt}$ until b_t), the intermediate cost shares peak at around 5,000 USD. For the rest of manufacturing, the strongest are

${ }^{6}$ The table includes per capita income levels beyond what is found in the GTAP Data Base to cover the range of projected income in simulations with G-RDEM 
typically found at the low income levels, although differences in the shares are often not very large.

There is also no uniform tendency for electricity, gas and water distribution activities (ely, gas, wtr) and construction (cns), where intermediate shares peak at medium income levels. Interestingly, results for all service industries (rows trd until osg) highlight a clear direction: intermediate shares increase at higher per capita income levels. Especially high shares are found in the transportation services (otp, wtp, atp), which are around $80 \%$, while the remaining services typically reach values around $50 \%$. 
Journal of Global Economic Analysis, Volume 4 (2019), No. 1, pp. 50-96.

Table 6: Intermediate costs shares in total and for the 57 GTAP sectors, mean, max and min estimates at increasing per capita GDP level in USD 2011

\begin{tabular}{|c|c|c|c|c|c|c|c|c|c|c|}
\hline & mean & $\max$ & $\min$ & 500 & 1,000 & 5,000 & 10,000 & 50,000 & 100,000 & \\
\hline tot & 0,515 & 0,669 & 0,291 & 0,495 & 0,524 & 0,568 & 0,558 & 0,475 & 0,421 & \\
\hline $\mathrm{pdr}$ & 0,460 & 0,992 & 0,043 & 0,264 & 0,269 & 0,296 & 0,328 & 0,478 & 0,596 & ++ \\
\hline wht & 0,571 & 1,000 & 0,001 & 0,637 & 0,592 & 0,499 & 0,463 & 0,390 & 0,363 & -- \\
\hline gro & 0,425 & 0,957 & 0,001 & 0,275 & 0,303 & 0,377 & 0,414 & 0,515 & 0,566 & ++ \\
\hline$v_{-} f$ & 0,361 & 0,847 & 0,002 & 0,177 & 0,200 & 0,263 & 0,296 & 0,391 & 0,440 & ++ \\
\hline osd & 0,451 & 0,994 & 0,011 & 0,249 & 0,255 & 0,288 & 0,328 & 0,529 & 0,701 & ++ \\
\hline c_b & 0,442 & 0,989 & 0,029 & 0,300 & 0,303 & 0,317 & 0,333 & 0,398 & 0,441 & ++ \\
\hline $\mathrm{pfb}$ & 0,535 & 0,998 & 0,044 & 0,286 & 0,341 & 0,472 & 0,497 & 0,458 & 0,405 & $* *$ \\
\hline ocr & 0,325 & 0,869 & 0,008 & 0,227 & 0,230 & 0,245 & 0,263 & 0,337 & 0,391 & $* *$ \\
\hline ctl & 0,520 & 0,989 & 0,046 & 0,378 & 0,386 & 0,430 & 0,483 & 0,737 & 0,946 & ++ \\
\hline oap & 0,546 & 0,984 & 0,066 & 0,362 & 0,402 & 0,513 & 0,570 & 0,727 & 0,807 & ++ \\
\hline rmk & 0,546 & 0,999 & 0,106 & 0,276 & 0,315 & 0,427 & 0,488 & 0,662 & 0,756 & ++ \\
\hline wol & 0,765 & 0,996 & 0,173 & 0,816 & 0,719 & 0,589 & 0,598 & 0,788 & 0,982 & ++ \\
\hline Frs & 0,399 & 0,986 & 0,002 & 0,142 & 0,171 & 0,259 & 0,311 & 0,472 & 0,566 & ++ \\
\hline Fsh & 0,481 & 0,952 & 0,020 & 0,248 & 0,277 & 0,359 & 0,402 & 0,522 & 0,584 & ++ \\
\hline coa & 0,561 & 1,000 & 0,037 & 0,480 & 0,419 & 0,348 & 0,372 & 0,608 & 0,869 & + \\
\hline oil & 0,433 & 1,179 & 0,027 & 0,514 & 0,399 & 0,255 & 0,246 & 0,325 & 0,429 & - \\
\hline gas & 0,471 & 1,265 & 0,018 & 0,320 & 0,320 & 0,320 & 0,320 & 0,320 & 0,320 & \\
\hline omn & 0,528 & 1,000 & 0,071 & 0,411 & 0,427 & 0,466 & 0,484 & 0,528 & 0,548 & ++ \\
\hline $\mathrm{cmt}$ & 0,729 & 0,995 & 0,307 & 0,736 & 0,736 & 0,736 & 0,736 & 0,736 & 0,736 & \\
\hline omt & 0,726 & 1,008 & 0,223 & 0,763 & 0,763 & 0,763 & 0,763 & 0,763 & 0,763 & \\
\hline vol & 0,784 & 0,999 & 0,358 & 0,813 & 0,813 & 0,813 & 0,813 & 0,813 & 0,813 & \\
\hline mil & 0,752 & 0,947 & 0,440 & 0,726 & 0,747 & 0,784 & 0,787 & 0,761 & 0,737 & + \\
\hline pcr & 0,771 & 1,000 & 0,224 & 0,728 & 0,754 & 0,780 & 0,753 & 0,615 & 0,536 & \\
\hline sgr & 0,662 & 1,006 & 0,141 & 0,684 & 0,722 & 0,760 & 0,720 & 0,530 & 0,430 & - \\
\hline ofd & 0,690 & 0,968 & 0,417 & 0,738 & 0,751 & 0,756 & 0,732 & 0,625 & 0,563 & - \\
\hline b_t & 0,603 & 0,897 & 0,146 & 0,565 & 0,599 & 0,656 & 0,649 & 0,565 & 0,506 & - \\
\hline
\end{tabular}

Note: +/- depicts the cases the estimate cost share at the highest income is higher/lowest than at the lowest

$++/--$ depicts cases where the share is estimated to in/decrease over the whole income range. The sector labels follow the convention in the GTAP Data Base. 
Journal of Global Economic Analysis, Volume 4 (2019), No. 1, pp. 50-96.

Table 7: Intermediate costs shares in total and for the 57 GTAP sectors, mean, max and min estimates at increasing per capita GDP level in USD 2011 (Continued)

\begin{tabular}{|c|c|c|c|c|c|c|c|c|c|c|}
\hline & mean & $\max$ & $\min$ & 500 & 1,000 & 5,000 & 10,000 & 50,000 & 100,000 & \\
\hline tex & 0,664 & 0,952 & 0,272 & 0,693 & 0,710 & 0,724 & 0,704 & 0,605 & 0,546 & - \\
\hline wap & 0,632 & 0,974 & 0,237 & 0,726 & 0,710 & 0,673 & 0,658 & 0,624 & 0,610 & -- \\
\hline lea & 0,669 & 1,000 & 0,275 & 0,713 & 0,710 & 0,693 & 0,677 & 0,619 & 0,587 & -- \\
\hline lum & 0,680 & 0,979 & 0,295 & 0,625 & 0,646 & 0,683 & 0,681 & 0,637 & 0,603 & - \\
\hline ppp & 0,650 & 0,950 & 0,339 & 0,692 & 0,708 & 0,714 & 0,685 & 0,557 & 0,486 & - \\
\hline p_c & 0,860 & 1,374 & 0,418 & 0,939 & 0,935 & 0,915 & 0,894 & 0,820 & 0,780 & -- \\
\hline crp & 0,732 & 1,000 & 0,395 & 0,772 & 0,769 & 0,750 & 0,730 & 0,663 & 0,626 & - \\
\hline $\mathrm{nmm}$ & 0,657 & 1,000 & 0,235 & 0,729 & 0,705 & 0,653 & 0,631 & 0,584 & 0,565 & -- \\
\hline i_s & 0,778 & 0,998 & 0,411 & 0,795 & 0,792 & 0,774 & 0,757 & 0,694 & 0,660 & \\
\hline $\mathrm{nfm}$ & 0,764 & 0,999 & 0,457 & 0,792 & 0,785 & 0,769 & 0,762 & 0,746 & 0,740 & -- \\
\hline fmp & 0,680 & 0,998 & 0,294 & 0,739 & 0,733 & 0,703 & 0,672 & 0,570 & 0,518 & -- \\
\hline $\mathrm{mvh}$ & 0,723 & 1,000 & 0,270 & 0,750 & 0,750 & 0,750 & 0,750 & 0,750 & 0,750 & \\
\hline otn & 0,679 & 1,070 & 0,236 & 0,734 & 0,716 & 0,677 & 0,661 & 0,625 & 0,610 & -- \\
\hline ele & 0,694 & 0,999 & 0,197 & 0,857 & 0,809 & 0,724 & 0,709 & 0,716 & 0,739 & - \\
\hline ome & 0,686 & 0,999 & 0,240 & 0,801 & 0,764 & 0,686 & 0,655 & 0,588 & 0,561 & -- \\
\hline omf & 0,679 & 0,999 & 0,167 & 0,752 & 0,711 & 0,635 & 0,615 & 0,596 & 0,599 & -- \\
\hline ely & 0,672 & 1,004 & 0,119 & 0,638 & 0,674 & 0,711 & 0,672 & 0,491 & 0,396 & - \\
\hline$g d t$ & 0,529 & 1,194 & 0,101 & 0,343 & 0,404 & 0,547 & 0,572 & 0,522 & 0,461 & + \\
\hline wtr & 0,463 & 0,951 & 0,002 & 0,422 & 0,422 & 0,422 & 0,422 & 0,422 & 0,422 & \\
\hline cns & 0,601 & 0,858 & 0,243 & 0,594 & 0,609 & 0,621 & 0,605 & 0,521 & 0,471 & - \\
\hline $\operatorname{trd}$ & 0,429 & 0,842 & 0,083 & 0,296 & 0,316 & 0,367 & 0,391 & 0,455 & 0,485 & ++ \\
\hline otp & 0,603 & 0,986 & 0,255 & 0,520 & 0,533 & 0,564 & 0,579 & 0,613 & 0,628 & ++ \\
\hline wtp & 0,710 & 0,988 & 0,291 & 0,509 & 0,532 & 0,591 & 0,618 & 0,686 & 0,718 & ++ \\
\hline atp & 0,733 & 1,051 & 0,324 & 0,583 & 0,610 & 0,678 & 0,710 & 0,789 & 0,826 & ++ \\
\hline $\mathrm{cmn}$ & 0,393 & 0,702 & 0,113 & 0,271 & 0,295 & 0,361 & 0,393 & 0,481 & 0,524 & ++ \\
\hline ofi & 0,383 & 0,912 & 0,000 & 0,232 & 0,236 & 0,260 & 0,287 & 0,417 & 0,519 & ++ \\
\hline isr & 0,461 & 0,911 & 0,000 & 0,253 & 0,308 & 0,450 & 0,487 & 0,482 & 0,441 & + \\
\hline obs & 0,381 & 0,740 & 0,079 & 0,383 & 0,383 & 0,383 & 0,383 & 0,383 & 0,383 & \\
\hline ros & 0,447 & 0,964 & 0,025 & 0,405 & 0,407 & 0,419 & 0,432 & 0,483 & 0,516 & ++ \\
\hline osg & 0,332 & 0,659 & 0,025 & 0,232 & 0,245 & 0,280 & 0,296 & 0,338 & 0,358 & ++ \\
\hline dwe & 0,142 & 0,483 & 0,000 & 0,090 & 0,090 & 0,090 & 0,090 & 0,090 & 0,090 & \\
\hline
\end{tabular}

sector labels follow the convention in the GTAP Data Base.

Source: Author calculation`s. 


\subsection{Intermediate input coefficients}

If preferences are a function of income per capita, reflected in non-linear Engel curves, then the portfolio of products offered by the economy clearly changes. As Chenery et al. (1986) put it "On the demand side, a rise in income can only be sustained if the goods and services made available correspond to the proportions in which consumers wish to spend their income". We already addressed this issue for the final demand through the introduction of an AIDADS demand system, but further adjustments are in order on the production side, to account for incomedependent variations in intermediate demand. Indeed, an often neglected aspect in CGE and input-output models is that industries internally include many diverse production processes, characterized by different technologies. Variations in demand patterns therefore occur not only between the macro-industries, but also inside them: aggregate industrial cost structures should be better interpreted as reflecting the internal composition of a sector, rather than describing the production function of a representative firm. Consequently, input-output coefficients can well evolve over time, following changes in income, prices, foreign trade, demography, etc., in a way not too different from the one affecting household final consumption. In parallel, processes such as capital accumulation and the related shift to more capital based production technologies can systematically affect the cost shares in certain industries.

Already Arrow and Hoffenberg (1959) decomposed changes in input-output coefficients into variations due to real disposable income and variations due to technology and tastes. Carter (1970) as well as Bezdek and Durham (1978), drawing on IO-tables for the U.S. over several decades, aggregate commodities to some broader categories and find some trends in changes in overall intermediate output requirements such as increases in the demand for semi-finished production inputs. Skolka (1989) further provided a structural decomposition analysis for Austria along these lines, thereby explicitly considering that I-O coefficients are not static, but actually change along the process of economic development. This contrasts with the approach followed in most dynamic CGE models, where changes in the industrial cost shares are only attributed to two causes: nonHicksian technological progress and changes in relative prices.

As an example, consider the "Other food" sector in GTAP, comprising a wide range of processing activities of crop and fish based products. Here the ICP data set, which was used to estimate the AIDADS demand system, includes expenditure data of subcategories such as "bread", "Other bakery products", "Pasta products", “"Jams, marmalades and honey", "Confectionery, chocolate and ice cream" etc. A simple regression on the shares of more disaggregated data relative to totals reveals that they typically are income dependent. As some of these categories require different inputs in production and are based on different 
technological processes, also the I-O composition of the "Other food" industry should hence be income dependent.

Therefore, I-O coefficients should be not considered as constant in the longterm, where income varies significantly. Since the model already accounts for price-induced compositional changes in intermediate demand, and possibly Hicksian non-neutral technical progress, we include in G-RDEM the modelling of income-related variations.

\subsection{Econometric analysis}

Our basic hypothesis is that I-O coefficients are income dependent, likewise final consumption shares. Since the GTAP Data Base does provide data on IOcoefficients for the three time points 2004, 2007 and 2011, only, where often underlying I-O tables have not changed while an alternative time series data base consistent with the GTAP industrial classification is not available, we test our hypothesis using a cross-sectional approach, using once more the GTAP Data Base Version 9, as we did for the intermediate composite. From the 3,249 I-O coefficients (57x57) in the GTAP Data Base, the model selection process analogue to (11) filtered a significant relation to GDP per capita in as many as 3,213 of them. The histogram in Figure 9, showing the significance levels, highlights that for more than two thirds of elements in the sample they are significant at $1 \%$ level or below.

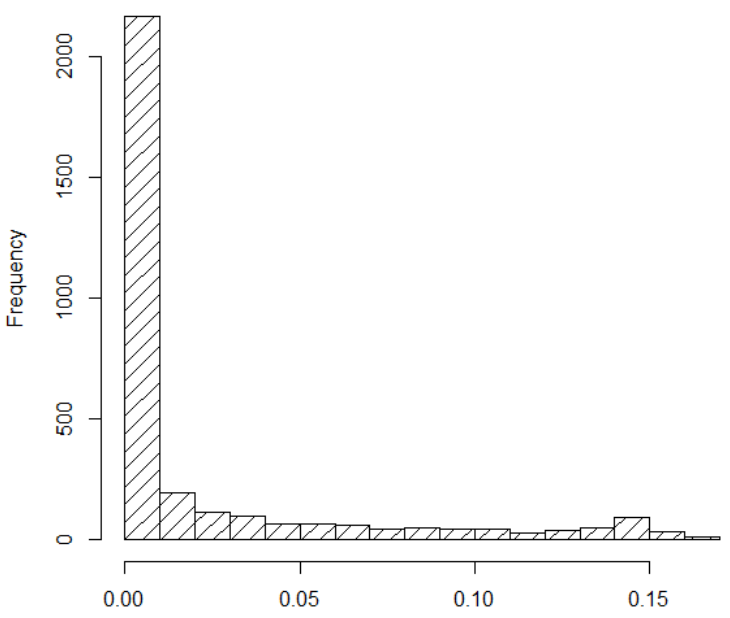

Figure 9 : p_value of regression coefficients of per capita income for individual input coefficients

Source: Author calculation`s.

Consider the agricultural "coarse grains" industry as an example, and its six largest cost shares (see Table 8). For two of them, corresponding to seeds (gro) and transport (otp), there is no clear income dependence. Services (obs, ofi) tend to grow with higher per capita income, whereas shares of chemical (crp) and petroleum (p_c) products peak at medium income levels and decrease at higher 
ones. Coarse grains could hence been seen as an example where economic development, through changes in technology - intensification in crop production by using more fertilizers, machinery etc. - and outsourcing of activities (contract work) drive differences in costs shares.

Table 8: Main cost shares in coarse grains as a function of per capita income

\begin{tabular}{|l|lll|llllll|}
\cline { 2 - 10 } \multicolumn{1}{c|}{} & mean & max & min & $\mathbf{5 0 0}$ & $\mathbf{1 . 0 0 0}$ & $\mathbf{5 . 0 0 0}$ & $\mathbf{1 0 . 0 0 0}$ & $\mathbf{5 0 . 0 0 0}$ & $\mathbf{1 0 0 . 0 0 0}$ \\
\hline crp & 0.173 & 0.666 & 0.000 & 0.113 & 0.138 & 0.199 & 0.210 & 0.187 & 0.161 \\
trd & 0.048 & 0.611 & 0.000 & 0.041 & 0.041 & 0.047 & 0.053 & 0.083 & 0.109 \\
gro & 0.043 & 0.315 & 0.000 & 0.043 & 0.043 & 0.043 & 0.043 & 0.043 & 0.043 \\
p_c & 0.030 & 0.400 & 0.000 & 0.008 & 0.014 & 0.044 & 0.056 & 0.051 & 0.037 \\
otp & 0.027 & 0.118 & 0.000 & 0.027 & 0.027 & 0.027 & 0.027 & 0.027 & 0.027 \\
obs & 0.012 & 0.217 & 0.000 & 0.002 & 0.005 & 0.018 & 0.028 & 0.049 & 0.052 \\
ofi & 0.008 & 0.071 & 0.000 & 0.001 & 0.003 & 0.014 & 0.018 & 0.012 & 0.007 \\
\hline Sum & & & & 0.233 & 0.267 & 0.378 & 0.416 & 0.439 & 0.428 \\
\hline
\end{tabular}

Note: The labels refer to the product labels from the GTAP Data Base; income in 2011 USD.

Source: Author calculation`s.

\subsection{Integrating the estimates into the baseline construction}

Integration of the regression results in the model is not a trivial task, as shares found at the base year may deviate considerably from the estimates. One option is to realign estimates and data by adding an error term to the intercept in the regressions, while considering also the effect of changes.

This is necessary because, for example, absolute changes may lead to negative shares when the shares are small. On the other hand, relative changes would keep small shares forever small, much like as it happens for trade shares in the Armington formulation.

We therefore opt here for an approach where the error terms err are adjusted on the basis of the following equation, where inc stands for GDP per capita in the benchmark 0 and in the current simulation year $t$, whereas and refers to the share parameter for the intermediate composite:

$$
\text { and }_{\text {corr }}=a n d_{\text {est }}+\operatorname{err}\left(\max \left(0,1-\frac{1}{2} a b s\left[\frac{i n c_{t}-i n c_{0}}{i n c_{0}}\right]\right)\right)
$$

The error term at the benchmark is defined as:

$$
e r r_{j}^{(k)}=C_{j}^{(k)}-\exp \left(\alpha_{o j}+\alpha_{1 j} \log Y P C^{(k)}+\alpha_{2 j}\left(\log Y P C^{(k)}\right)^{2}\right)
$$

The idea behind the correction is simple: the farther away the given GDP per capita from the benchmark, the less structural information is provided by the initialSAM. Specifically, equation (12) defines a relation where at an income growth of 50\%, 
$75 \%$ of the error term will be added. If real income doubles, $50 \%$ is added and if income triples, the estimates are directly used.

A further complication is due to the fact that the cost share is not a given parameter but reflects price changes for the output and the intermediate input composite. The price variations for the intermediate composite ( $p n d)$ and the unit cost of output $(p x)$ need to be taken into account in the model. The cost share parameter and is therefore defined as:

$$
\text { and }_{\text {fin }}=\text { and }_{\text {corr }} \frac{p x}{p n d}
$$

Table 8 illustrates how we use equation 12 in making projections based on results taken from an example simulation over 40 years in four year steps. The label $\mathrm{t} 00$ indicates the benchmark (2011) and $\mathrm{t} 01$.. t 40 the simulated years, i.e. $\mathrm{t} 40$ refers to the year 2051. The estimated cost share at benchmark income is about $27 \%$ (row "Econometric estimate"), while the share found in the SAM is about 33\% (row "AND parameter"). That results in an error term of around 6\%. In the first simulation period ( $(04)$, the estimate increases only slightly, as also GDP per capita is not changing much. Accordingly, around $97 \%$ of the error term is kept, and the cost share only drops slightly towards the lower econometric estimate. The cost share parameter is further corrected stronger as the per unit price decreases to 0.93, lower than the intermediate composite price index (0.97). In year 28 of the simulation, GDP has tripled and the correction factor drops to zero. Accordingly, from there onwards, the cost share of the intermediate composite (row "ND cost share") is identical to the econometric estimate.

Table 9: Example of cost share parameter adjustment in simulation

\begin{tabular}{|l|llllllllllll|}
\cline { 2 - 10 } & t00 & t01 & t04 & t08 & t12 & t16 & t20 & t24 & t28 & t32 & t36 & t40 \\
\hline Econometric estimate & & 0,27 & 0,27 & 0,27 & 0,27 & 0,28 & 0,28 & 0,28 & 0,29 & 0,30 & 0,31 & 0,31 \\
pnd & & 1,00 & 0,98 & 0,81 & 0,73 & 0,69 & 0,66 & 0,68 & 0,67 & 0,70 & 0,75 & 0,82 \\
px & & 1,00 & 0,93 & 0,80 & 0,76 & 0,77 & 0,78 & 0,88 & 0,93 & 1,03 & 1,14 & 1,29 \\
Crror term & & 0,06 & 0,06 & 0,06 & 0,06 & 0,06 & 0,06 & 0,06 & 0,06 & 0,06 & 0,06 & 0,06 \\
GDP & 1,00 & 0,97 & 0,89 & 0,74 & 0,55 & 0,31 & 0,02 & & & & \\
AND parameter & 1,42 & 1,42 & 1,49 & 1,73 & 2,14 & 2,69 & 3,38 & 4,19 & 5,19 & 6,30 & 7,49 \\
ND cost share & 0,33 & 0,33 & 0,31 & 0,32 & 0,33 & 0,34 & 0,35 & 0,37 & 0,40 & 0,44 & 0,46 & 0,49 \\
\hline
\end{tabular}

Source: Author calculation`s.

The same approach is used to project the individual IO-coefficients. Here, additionally, the resulting estimates are scaled to unity. Further details about the methodology are provided in the supplementary material. 


\section{Assessing the G-RDEM model}

To illustrate how the particular features of the G-RDEM model affect the results, we present here a set of comparative simulation exercises, under different model configurations. We also contrast our findings with those obtained from a standard GTAP model, linked recursively over time only by a simple mechanism of capital accumulation. To this end, we use (for the initial parameters calibration) the global SAM of the GTAP Data Base Version 9 with full sectoral detail (57 industries) but 10 aggregated macro-regions. For the exogenous projections of GDP and population, we adopt the SSP3 scenario.

When all features of G-RDEM are "switched off", the model becomes a rather simple recursive-dynamic one. The key characteristics of the two model types are reported in Table 10. By selecting the various characteristics in G-RDEM, we obtain seven different model configurations: (1) the complete G-RDEM implementation with all its five features (AIDADS demand system, productivity shifters, updated saving rates, updated I-O coefficients, debt accumulation); (2) five versions of GRDEM, having only one of those modules active, and (3) the GTAP Recursive Dynamic variant, where only capital accumulation is considered and the demand system is a CDE (Constant Differences in Elasticity).

Table 10: Common and differentiated features of compared model layouts

\begin{tabular}{|c|c|c|}
\hline & GTAP-RecDyn & G-RDEM \\
\hline $\begin{array}{l}\text { Sector and regional } \\
\text { aggregation }\end{array}$ & \multicolumn{2}{|l|}{ GTAP 9, 57 sectors, 10 regions } \\
\hline Trade modelling & \multicolumn{2}{|c|}{ Aggregated Armington agents, two-level nesting } \\
\hline $\begin{array}{l}\text { Time horizon and } \\
\text { resolution }\end{array}$ & \multicolumn{2}{|l|}{40 years in four year steps } \\
\hline $\begin{array}{l}\text { Production function } \\
\text { nesting }\end{array}$ & \multicolumn{2}{|c|}{$\begin{array}{l}\text { Mild substitution between value added and the intermediate composite, } \\
\text { for value added: sub-nests between labour categories, between capital } \\
\text { and natural resources, and total labour and land } \\
\text { Mild substitution between intermediates } \\
\text { Sub-nests for agri products in feed and food processing with higher } \\
\text { substitution elasticity }\end{array}$} \\
\hline Demand & $\begin{array}{l}\text { CDE, CES sub-nests for cereals } \\
\text { and meats, and domestic vs. } \\
\text { import }\end{array}$ & $\begin{array}{l}\text { AIDADS, CES sub-nests for cereals } \\
\text { and meats, and domestic vs. import }\end{array}$ \\
\hline Productivity shifters & Uniform & $\begin{array}{l}\text { Differentiated for three major } \\
\text { sectors, depending on GDP growth }\end{array}$ \\
\hline Saving rates & Fixed, from calibration & $\begin{array}{l}\text { Driven by age composition, GDP } \\
\text { per capita and GDP growth }\end{array}$ \\
\hline I-O Coefficients & Fixed, from calibration & Driven by GDP per capita index \\
\hline $\begin{array}{l}\text { Foreign debt } \\
\text { accumulation }\end{array}$ & not considered & $\begin{array}{l}\text { considered, giving raise to interest } \\
\text { payments }\end{array}$ \\
\hline
\end{tabular}

Source: Author construction. 


\subsection{Differences between generated baselines - global scale}

As mentioned above, the following more detailed analysis, first at global (8.1) and next at regional level (8.2), refers to SSP3 before we compare a subset of results across SPPs in section 8.3.

Figure 10 shows the evolution of the aggregate capital stock, for the whole world, over the forty years simulation horizon (2011 - 2051, in four year steps) obtained from the six variants of G-RDEM and the simple recursive-dynamic GTAP model.

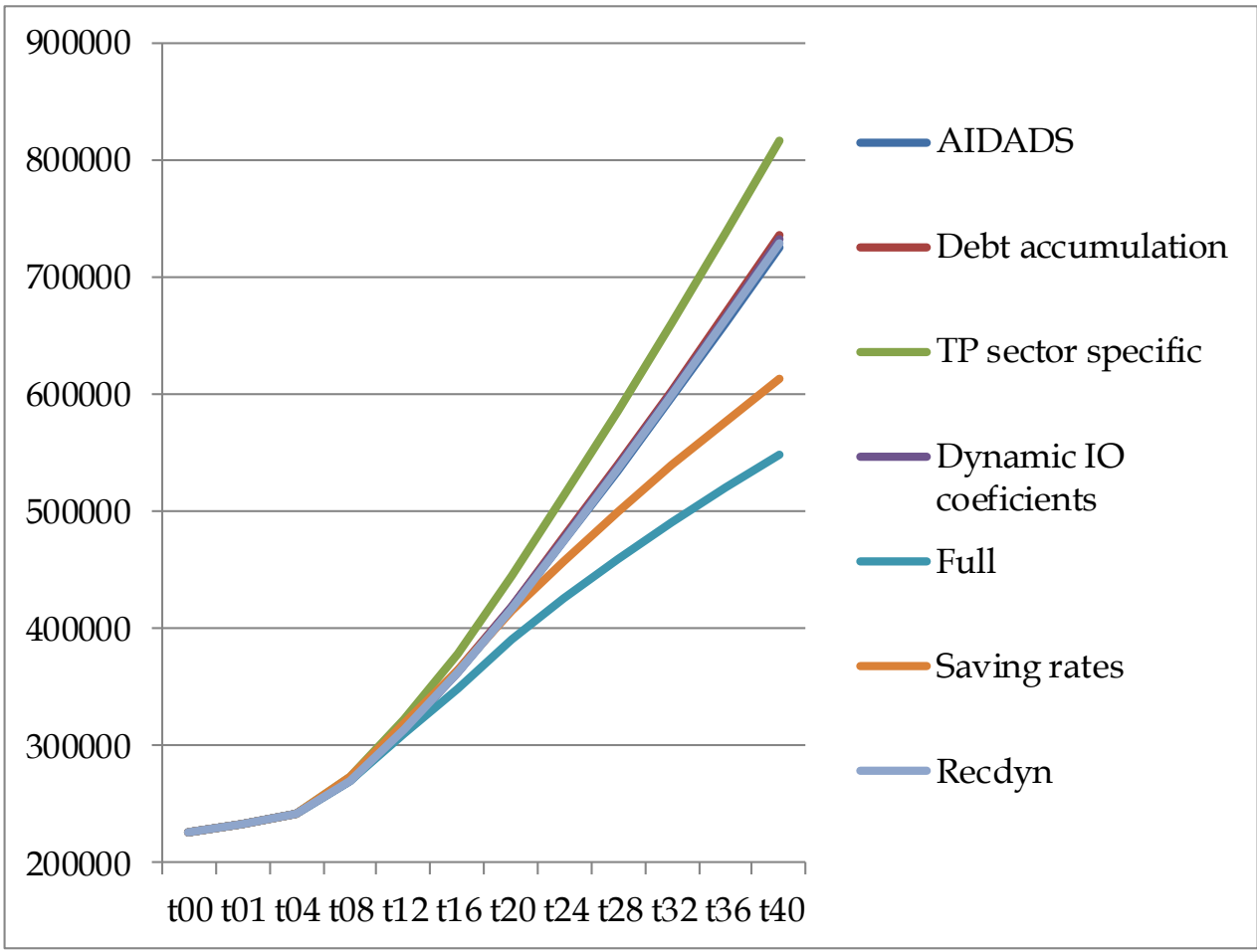

Figure 10 : Global capital stock projection, Bio USD 2011

Source: Author calculations.

We found that when savings rates are endogenously adjusted, whether in the full model version ("Full" in Figure 10 above) or when only this mechanism is taken into account ("Saving rates"), capital accumulation gets considerably lower. The reason is that both in the developed world, but also in important emerging economies such as China, demographic factors dampen the saving rates and thus the overall share of income spent on saving. Note again that, in the baseline 
construction, real GDP in each region is fixed, such that the lower capital accumulation must be offset by higher TFP.

The development of the capital stock in this case might fit better the assumed GDP dynamics of SSP3, which were generated by the OECD ENV-Growth model, and are shown in Figure 11. That scenario implies that global growth rates are relatively high up to around twenty years and flatten afterwards. The evolution of the capital stock in the full G-RDEM model (line "Full" in Figure 10 above) appears to follow a similar pattern.

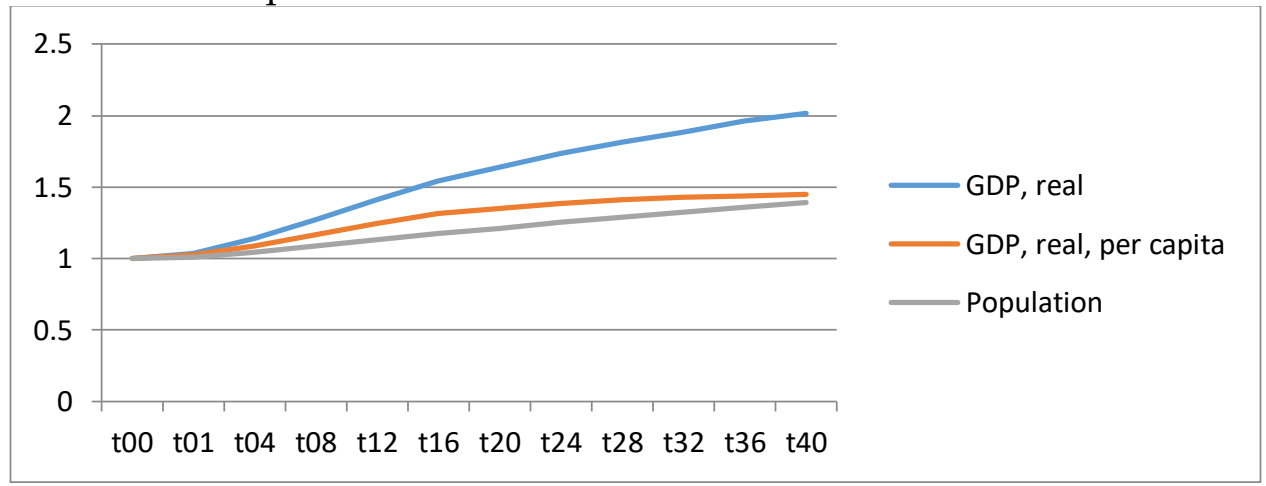

Figure 11 : GDP, Population and GDP per capita projections from SSP3

Source: Author calculations.

The lower capital accumulation in the full G-RDEM model is linked to a reduction in gross global savings (Figure 12), which equal global investments, therefore the growth in capital stock. But investments are also a component of the GDP. Since the latter is exogenously given, any reduction in investments must be compensated by increments in other elements, most notably private and public consumption. 


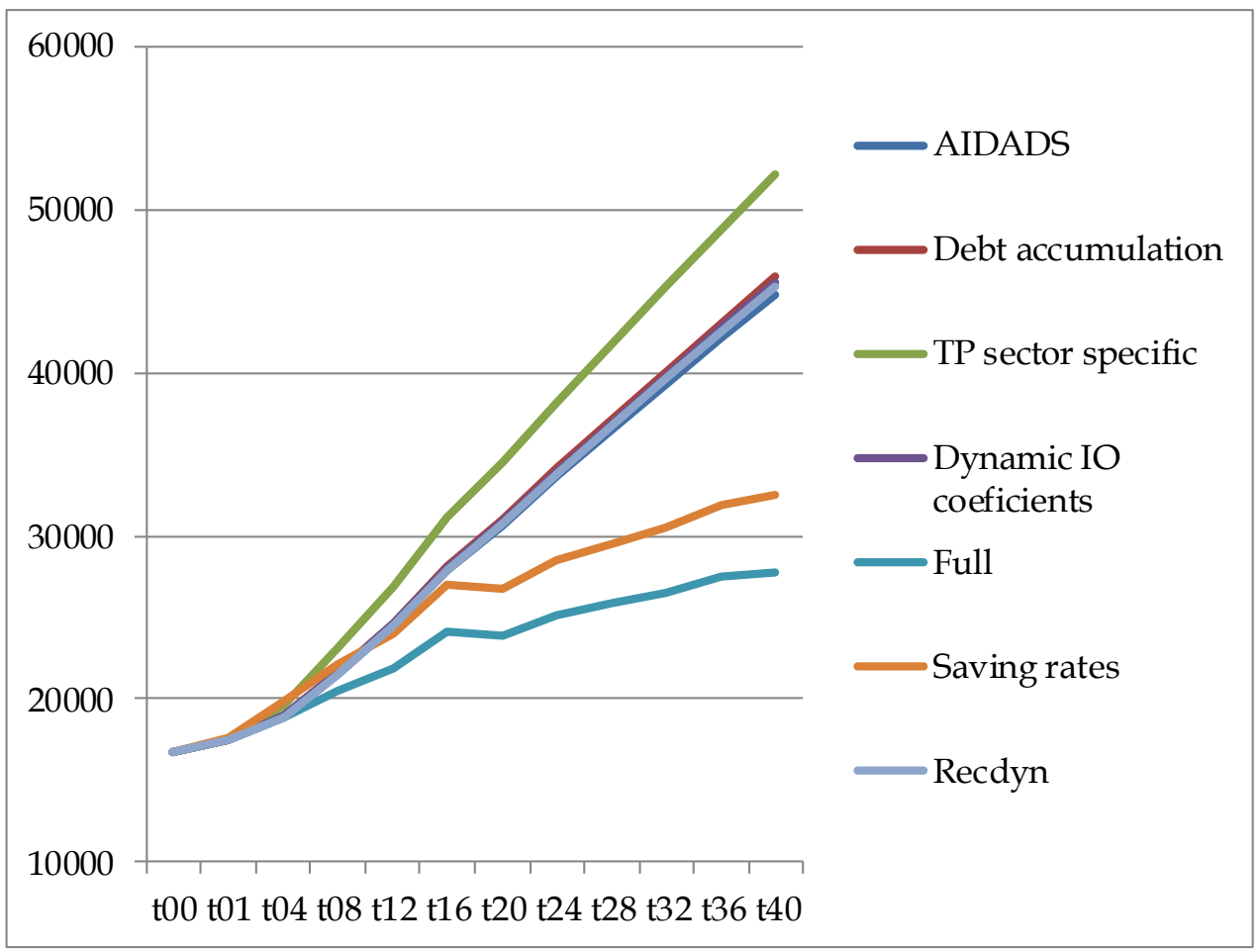

Figure 12: Aggregate gross investments, Bio USD 2011

Source: Author calculations.

Similarly, since a lower capital stock would bring about lower production output, ceteris paribus, a second compensation mechanism is needed to keep up with the given GDP growth: larger gains in TFP, which is endogenous during the generation of the baseline. This is necessary, because growth rates of other primary factor stocks, such as labour, are kept exogenous. To sum up, two immediate consequences of the slower capital accumulation, when GDP is given, are: more consumption (by private households and government) and higher productivity.

The effect of the reduced investments on private consumption is visualized in Figure 13. Consumption levels, however, are also affected by other effects. In particular, we found that interest payments on foreign debt somewhat reduce global consumption. A possible explanation is that countries which act as lenders - take China for example - have high aggregate saving rates. Increasing income flows to these regions might hence shift final consumption from private consumption to savings. 
Journal of Global Economic Analysis, Volume 4 (2019), No. 1, pp. 50-96.

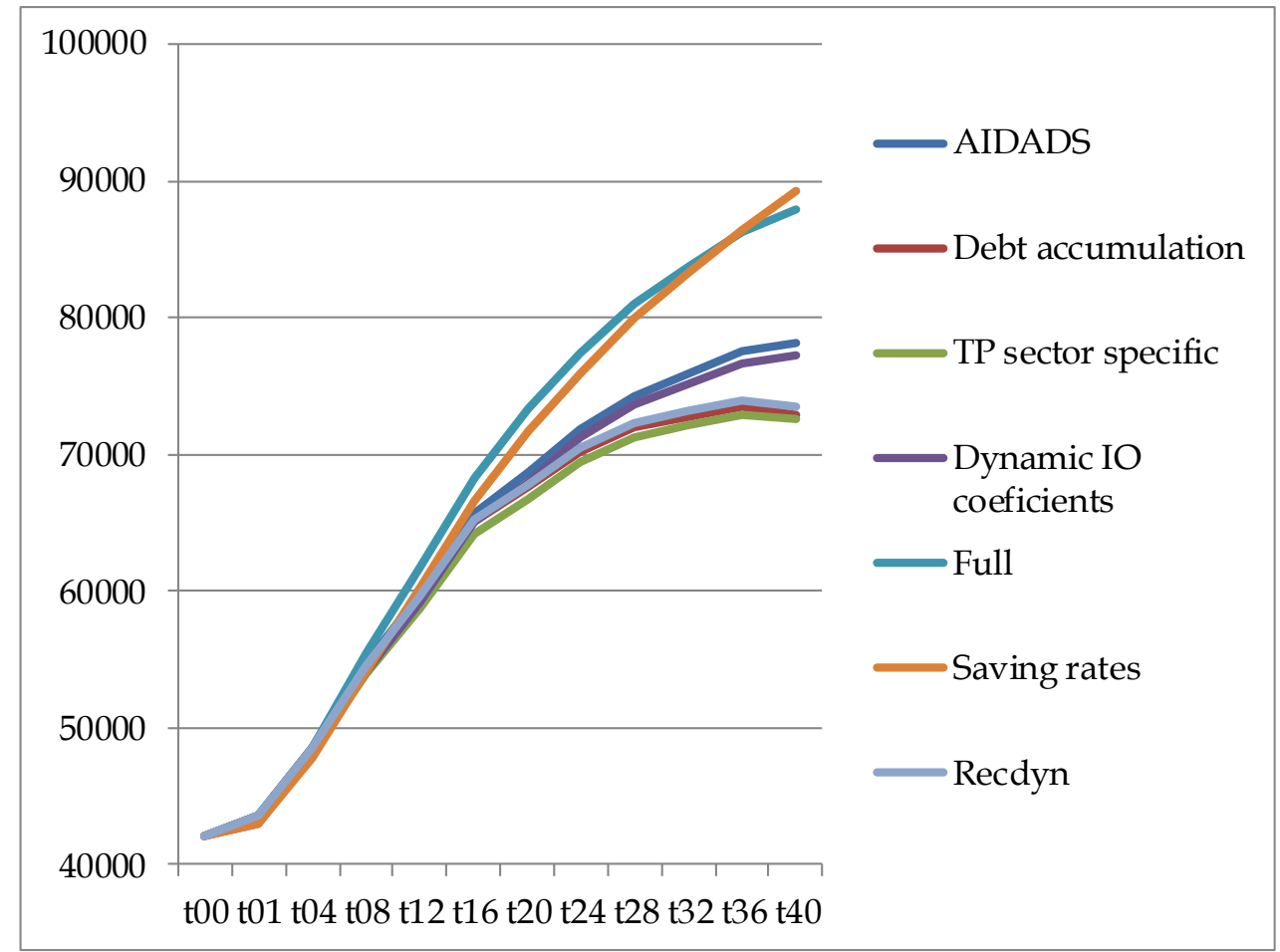

Figure 13: Aggregate global demand by private households, Bio USD 2011

Source: Author calculations.

We find that the complete G-RDEM model generates a somewhat smaller increase in intermediate demand than GTAP-RecDyn. This seems to be based on the interplay of almost all model features. Lower saving rates imply higher TFP growth, therefore less intermediate factors and changing cost shares, which on average reduce the amount of intermediates. The differentiated productivity growth alone would drive up the intermediate cost share, while the AIDADS demand system would slightly dampen it. 


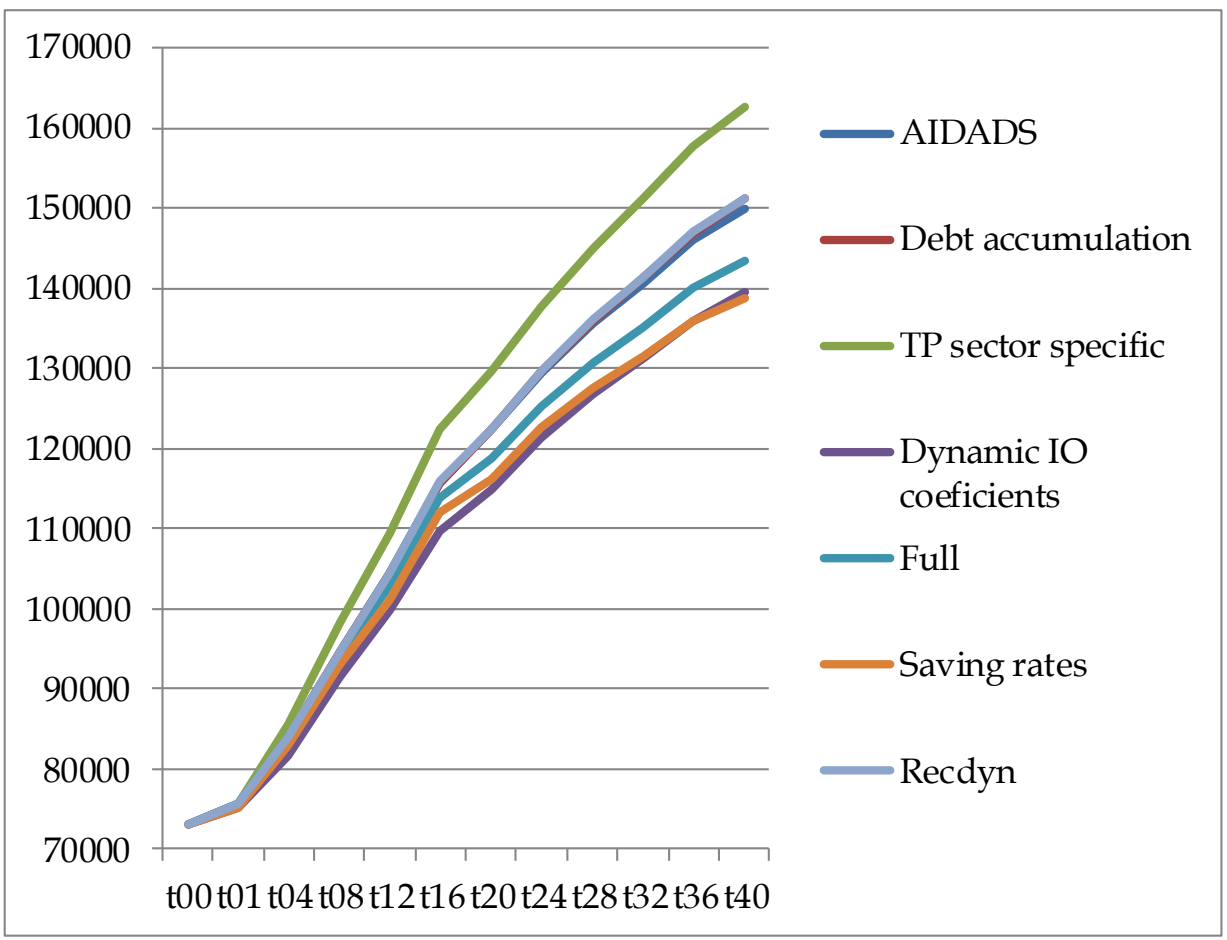

Figure 14: Aggregate intermediate demand, Bio USD 2011

Source: Author calculations.

\subsection{Regional and sectoral impacts}

We now turn to analyzing differences at the sectoral and regional level. Remind that regional GDP and population projections are identical across the variants, so that the various baselines only distribute the given regional growth differently between the sectors.

Table 11 below shows the differences in global production volumes for 10 aggregated sectors. It highlights that the demand system matters, especially for primary agricultural products (contrast AIDADS only with GTAP-RecDyn), while differences between other categories are less pronounced.

Some more differences can be found in the full implementation of G-RDEM. First, the reduced intermediate demand implies that global output gets lower by about $9 \%$. The reduction is especially evident in Light and Heavy Manufacturing, because these industries are mainly producing intermediates and because the differentiated productivity growth is stronger in the manufacturing sector. 
Table 11: Total global production of aggregate product categories [Mio US\$]

\begin{tabular}{|l|r|r|r|}
\hline & \multicolumn{2}{|l|}{ AIDADS } & Full \\
\hline Total & $\mathbf{2 9 7 0 2 4}$ & $\mathbf{2 8 3 4 3 5}$ & $\mathbf{2 9 8 6 4 0}$ \\
\hline Grains and Crops & 4548 & 4756 & 5385 \\
\hline $\begin{array}{l}\text { Livestock and Meat } \\
\text { Products }\end{array}$ & 3976 & 4379 & 4371 \\
\hline Mining and Extraction & 9877 & 11032 & 10053 \\
\hline Processed Food & 10103 & 13094 & 9558 \\
\hline Textiles and Clothing & 5273 & 6267 & 4956 \\
\hline Light Manufacturing & 27797 & 26653 & 27877 \\
\hline Heavy Manufacturing & 62017 & 56763 & 63821 \\
\hline $\begin{array}{l}\text { Utilities and } \\
\text { Construction }\end{array}$ & 33267 & 28429 & 33419 \\
\hline $\begin{array}{l}\text { Transport and } \\
\text { Communication }\end{array}$ & 48390 & 45728 & 49656 \\
\hline Other Services & 91776 & 86334 & 89543 \\
\hline
\end{tabular}

Source: Author calculations.

The indirect effect of considering non-linear Engel curves and other dynamic adjustments on specific variables can be quite pronounced, as shown below for the evolution of the price of land in the Sub-Saharan region (Figure 15). Both G-RDEM and a simple recursive-dynamic model predict increases, but the simpler model let the price increase by as much as $2000 \%$.

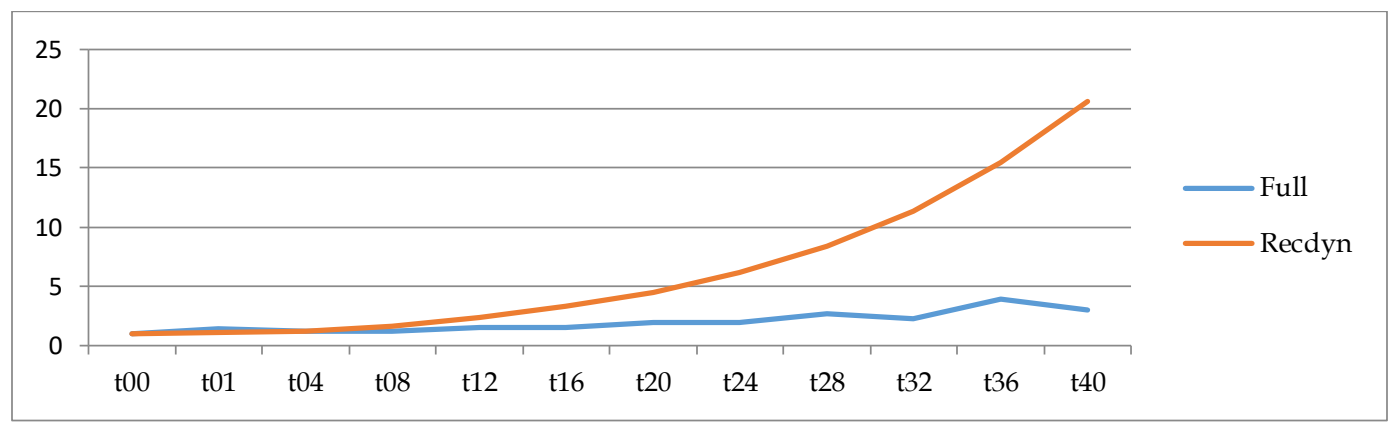

Figure 15: Land price development in Sub-Saharian Africa, relative to benchmark

Source: Author calculations.

The main underlying reason behind the differences has to do with the CDE and AIDADS demand systems. The latter considers consumption of grains and crops as rather income inelastic. As a consequence, per capita demand of the private household is projected to stay more or less stable (Figure 16) in G-RDEM; whereas the CDE system, along with its parameterization inherited from the standard 
GTAP model and used in the recursive dynamic version, exhibits a considerable growth.

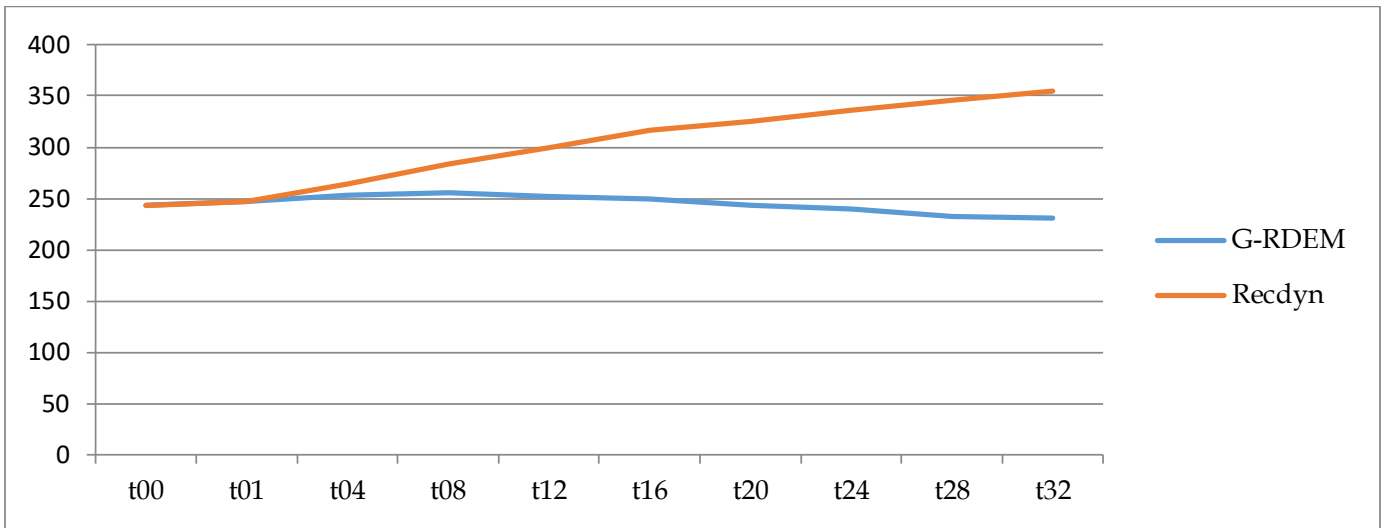

Figure 16: Per capita demand for grains and crops in Sub-Saharan Africa [USD 2011]

Source: Author calculations.

\subsection{Comparing the five SSPS}

We compare next some key results across different baselines, by applying the G-RDEM model to the macro-projections of each of the five SSPs. They are based on narratives describing broad socioeconomic trends that could shape future society. These are intended to span the range of plausible futures. They include: a world of sustainability-focused growth and equality (SSP1); a "middle of the road" world where trends broadly follow their historical patterns (SSP2); a fragmented world of "resurgent nationalism" (SSP3); a world of ever-increasing inequality (SSP4); and a world of rapid and unconstrained growth in economic output and energy use (SSP5). As graphically illustrated in Figure 17, the various scenarios are differentiated with respect to two main dimensions: socio-economic challenges (adaptation) and environmental challenges (mitigation). 


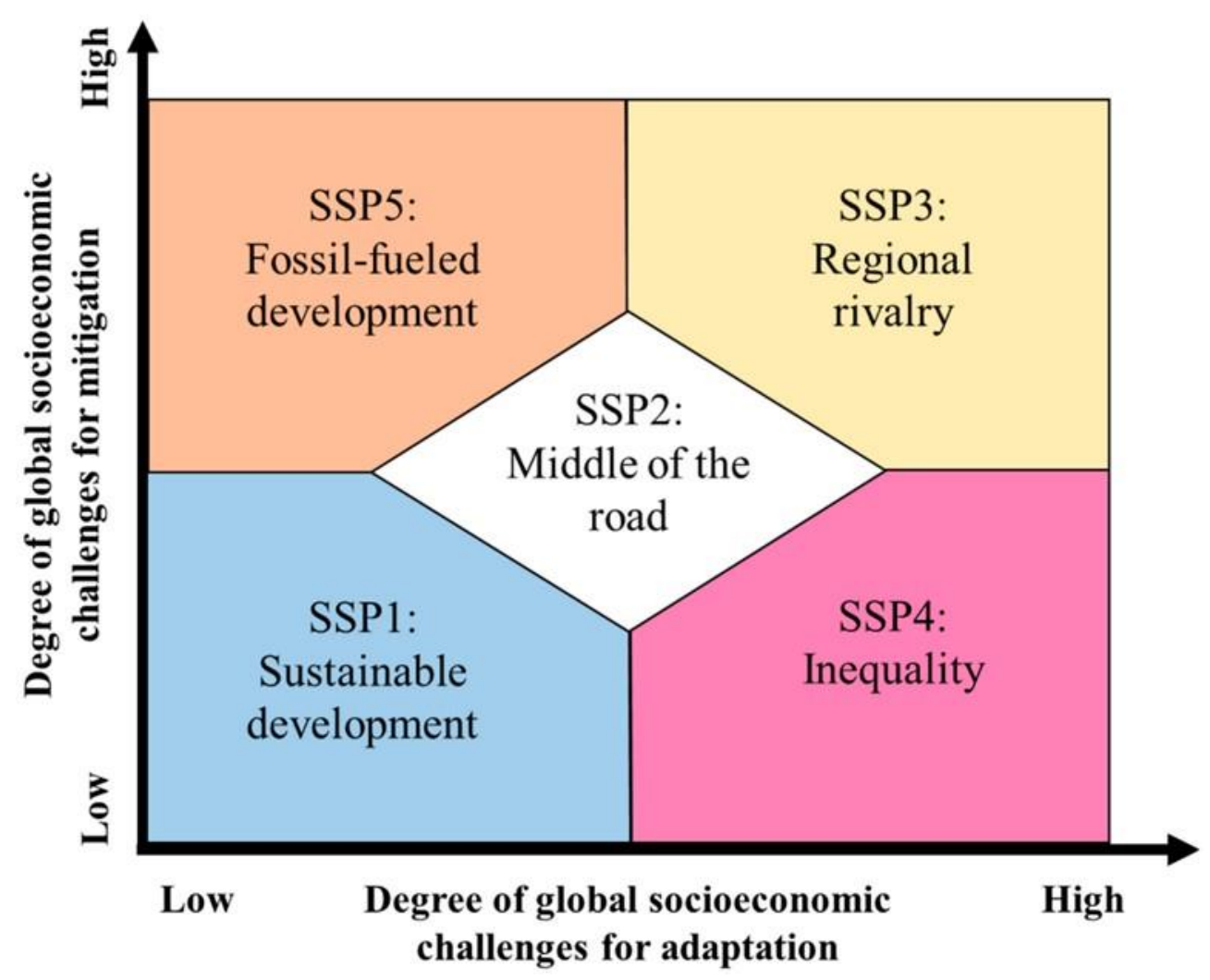

Figure 17: Graphical exposition of the SSP scenarios

Source: Sellers and Ebi, 2018

No further attempts are made to supplement these macro-projections with SSP specific changes in other exogenous parameters reflecting the underlying narratives. For instance, with regard to land use changes or investments in climate change abatement.

We first visualize (Figure 18) the major drivers in the SSPs: real GDP and population projections and, from there, real GDP per capita. We pick two quite different regions: the EU28, which is characterized by population losses in the long run and limited economic growth, and Sub-Saharan Africa with high population and economic dynamics. 


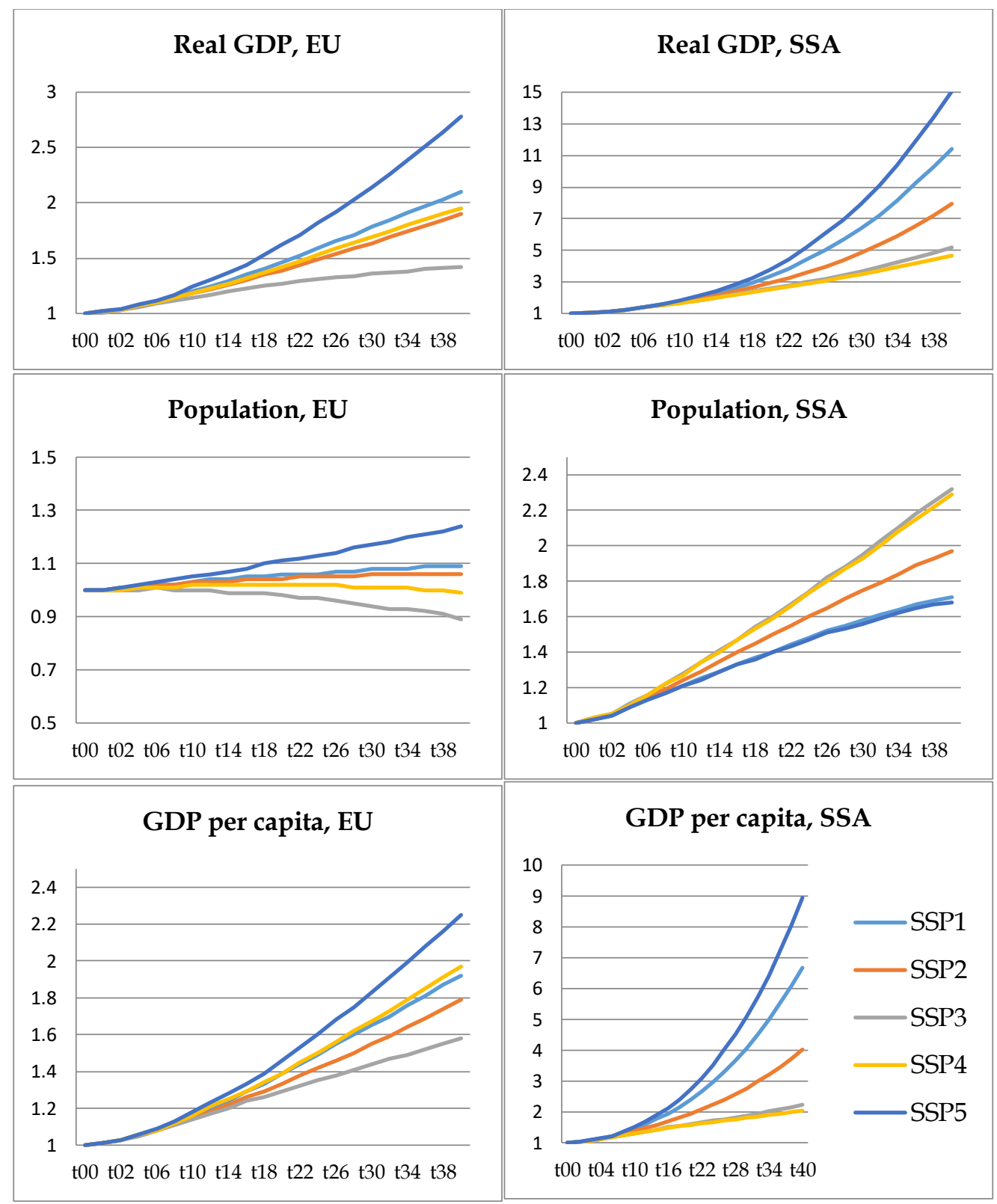

Figure 18: Relative changes in GDP, population and GDP per capita for Sub-Saharan Africa and the EU 28 for the five SSPs

Source: Author calculations.

The different GDP developments imply different compositions for per capita consumption in the long run. To see that, Figure 19: Per capita demand for wheat and dwellings refers to two products with quite different income elasticities. 


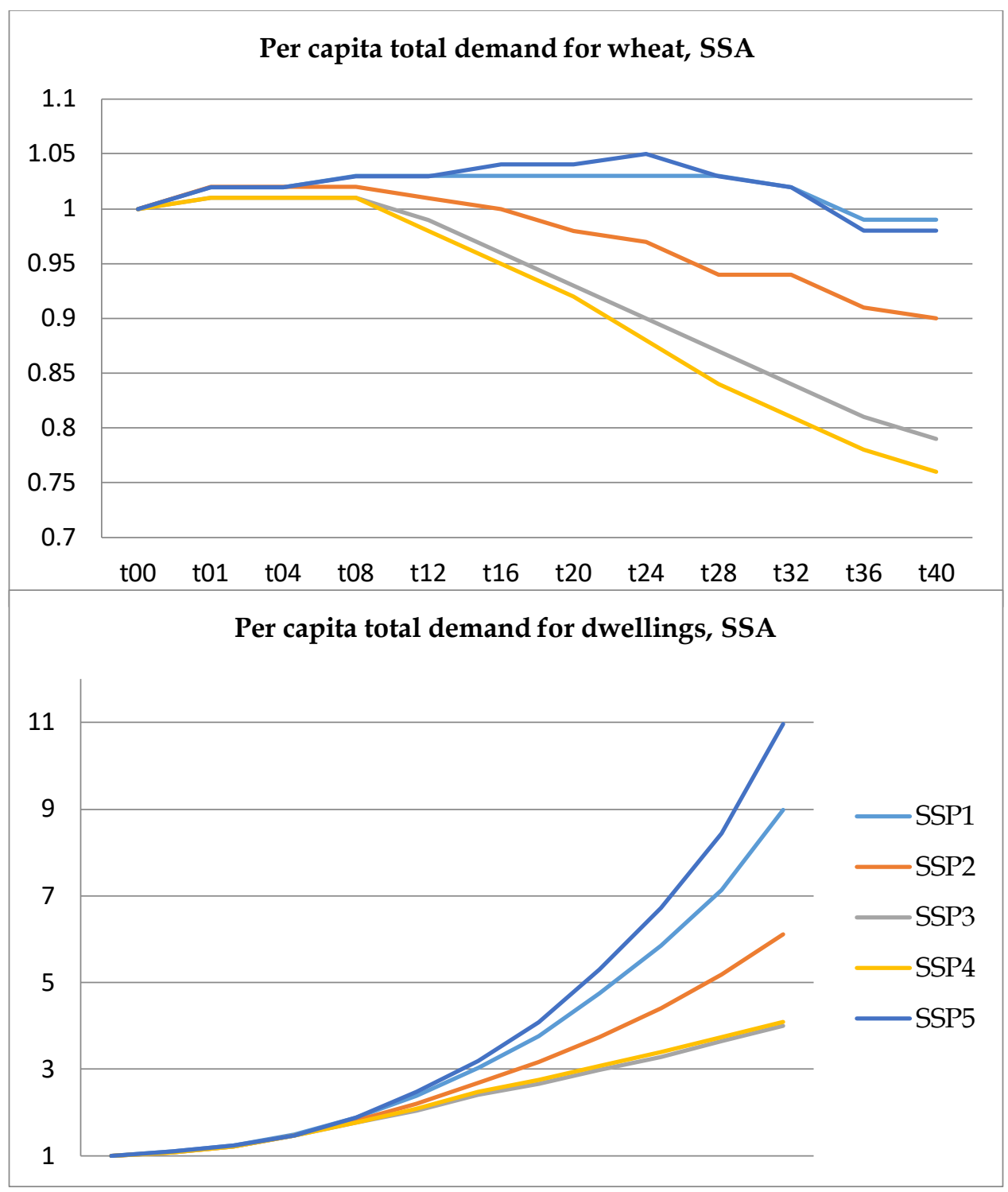

Figure 19: Per capita demand for wheat and dwellings

Source: Author calculations.

Average factor productivity is endogenously matching the given GDP growth scenario, while the differentiated productivity growth mechanism separately adjusts the overall development for the primary sector, manufacturing and the services. The extremely high GDP per capita projections for SSA require substantial productivity gains. Because of productivity differentials, these are mostly occurring in agriculture and manufacturing. On the other hand, the lower 
growth in the EU leads to a far smaller spread in TFP growth rates across the sectors.

Under the very optimistic growth projections of SSP5, SSA is envisaged to increase its productivity in manufacturing by a factor around twenty, to match the tremendous growth in total GDP.

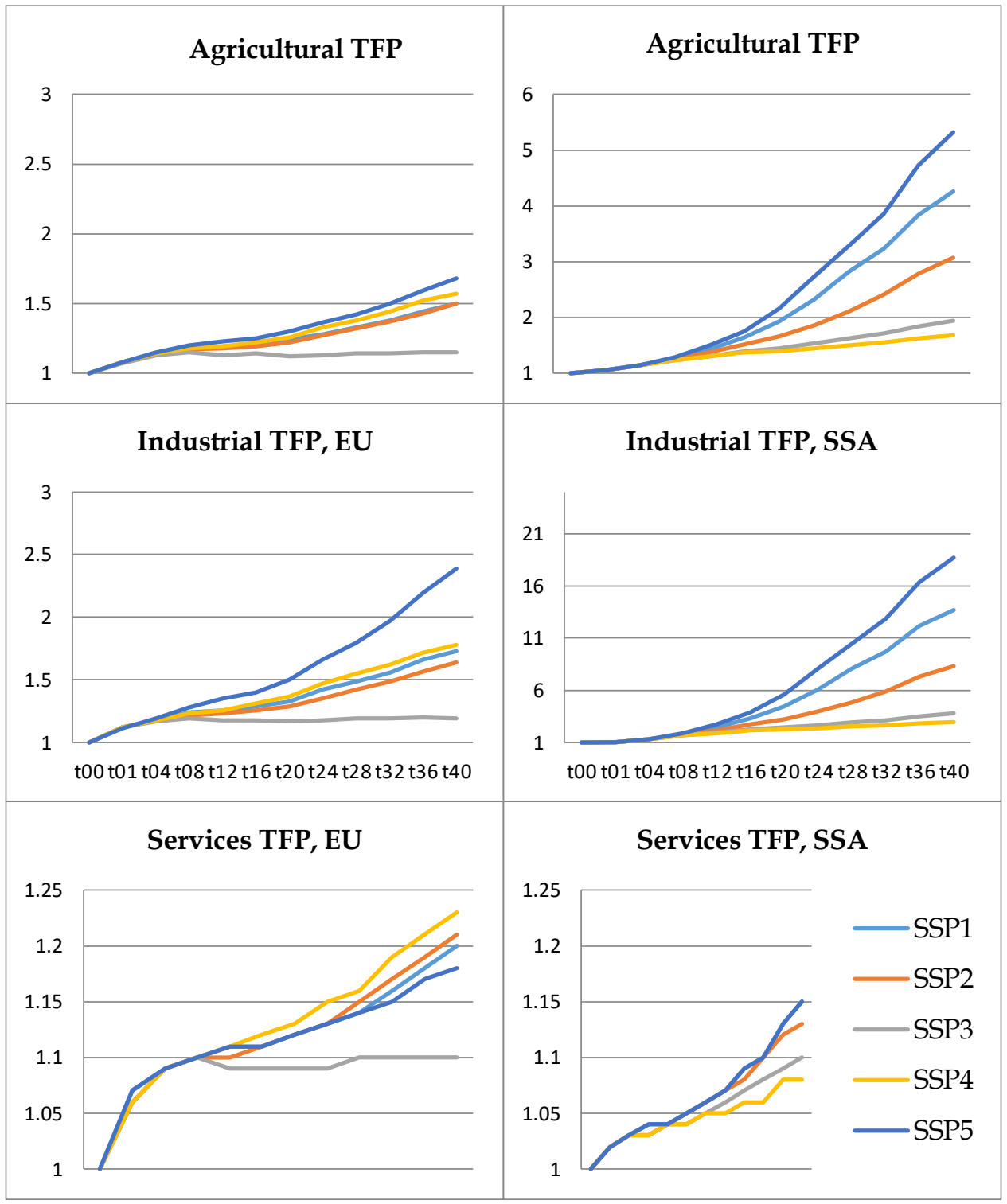

Figure 20: TFP change in three sectors, EU and Sub-Saharan Africa for the five SSPs Source: Author calculations.

Savings rates play a major role, as they drive capital accumulation, which in turn determines the capital stock in the economy (Figure 21), and therefore also 
determine the required TFP change. Higher capital accumulation implies lower factor productivity variations, to reach the same GDP growth. At the same time, changes in the savings rates also imply different shares on private and government consumption. For the EU, the changes in the dependency rates of an aging population drive the saving rates down, and only under SSP5 they remain close to their initial levels. The opposite dynamics can be observed in SSA, where saving rates reach levels currently observed in fast growing East-Asian economies.

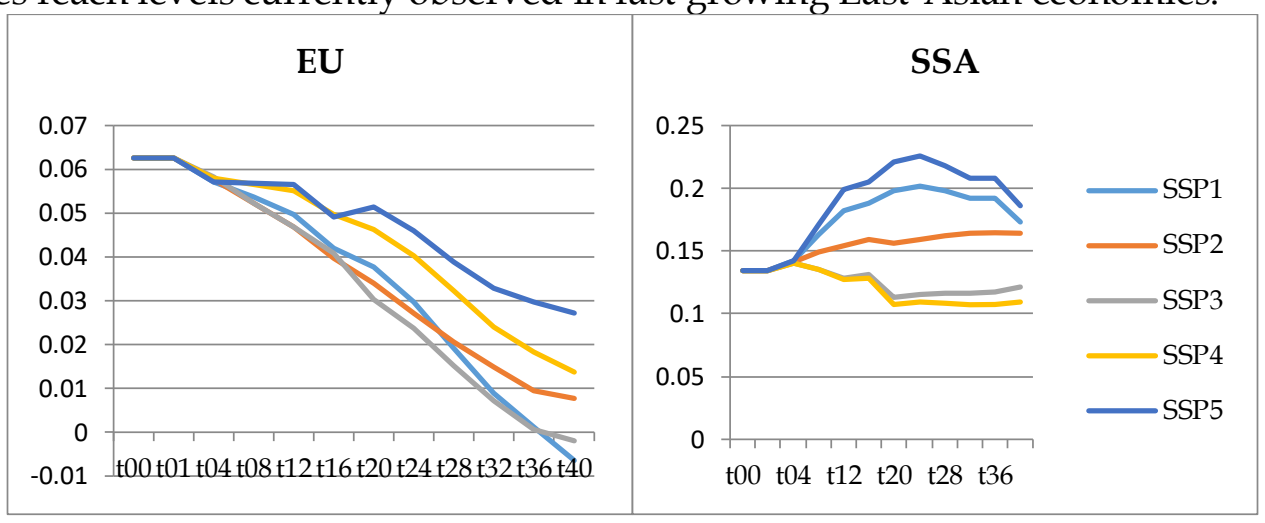

Figure 21: Saving rate for the EU 28 and Sub-Saharan Africa, for the five SSPs

Source: Author calculations.

The saving rate differences, in combination with the various GDP levels, imply quite different capital stocks (Figure 22), most notably in the long run. The capital stock in SSA shows a similar trajectory as GDP (see figure 18), but at a lower growth rate. The opposite can be observed in the EU: the capital stock grows faster than GDP, despite lower saving rates, implying a trade deficit such that foreign savings offset the reduced regional savings.

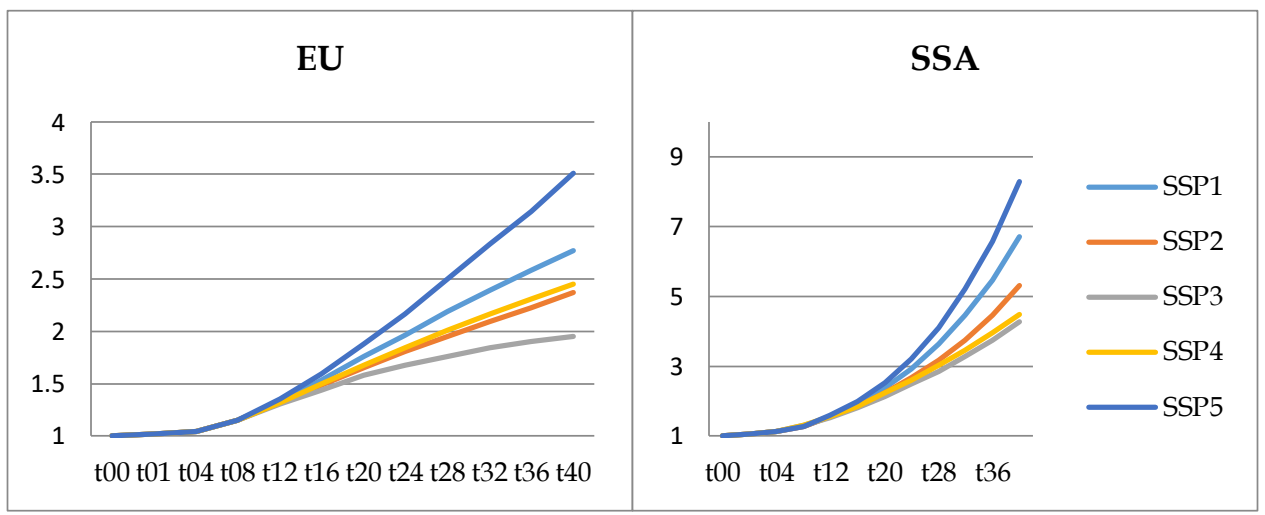

Figure 22: Capital stock development for the EU 28 and Sub-Saharan Africa for the five SSPs

Source: Author calculations. 


\section{Summary and conclusion}

G-RDEM (GTAP-derived Recursive Dynamic Extended Model) is a dynamic CGE model explicitly developed to generate baselines and to study long-term structural change processes. It is designed to be driven by exogenous projections of some macroeconomic aggregates. In this paper, baselines were generated on the basis of exogenously given regional GDP and population, as specified in the Shared Socio-Economic Pathways. However, other drivers may be considered, like productivity or resource endowments.

G-RDEM is characterized five salient features: an AIDADS demand system with non-linear Engel curves, productivity growth differentiated by sector, income and population composition dependent saving rates, debt accumulation from foreign savings and dynamic cost shares. These features are parameterized drawing on own empirical work or available literature. Alternative implementations are found in literature and partly discussed above, they might work at least as well as ours. As these feature are transparently integrated into the flexible and modular modelling platform CGEBox, developing and testing alternatives or improvements in detail should be rather straightforward. We therefore explicitly invite other modelers to contribute to the further development of G-RDEM for instance by updating more parameters during simulation based on econometric work or existing literature.

We have assessed the newly develop tool by comparing results for a baseline under the SSP3 scenario, against a simpler recursive-dynamic model, derived from the standard GTAP one. We regard the results from G-RDEM as more plausible and informative. Compared to the more conventional model, we found that the economy moves away from primary agriculture and food, and accumulates less capital. The reduced capital stock also implies that total factor productivity must contribute more to growth, which reduces intermediate demand and output volumes.

In addition, we have also shown how G-RDEM can be employed to highlight some key differences among SSP scenarios at the regional level, especially when comparing developed and developing countries, such as European Union versus Sub-Saharan Africa.

\section{Acknowlegdements}

We thank two reviewers for their valuable comments and suggestions. Special thanks also to the colleagues at IIASA for their SSP data portal without that this work would not have been possible.

\section{References}

Aguiar, A., Narayanan, B., \& McDougall, R. (2016). An Overview of the GTAP 9 Data Base. Journal of Global Economic Analysis, 1(1), 181-208. 
Alexandratos, N., Bruinsma, J. (2012). World agriculture towards 2030/2050: the 2012 revision (Vol. 12, No. 3). FAO, Rome: ESA Working paper.

Arrow, K. J., Hoffenberg, M. (1959). A time series analysis of interindustry demands (Vol. 17). North-Holland.

Baumol, W. J. (1986). Productivity Growth, Convergence and Welfare: What the Long-Run Data Show. The American Economic Review 76 (5), 1072-1085.

Bezdek, R. H., \& Dunham, C. R. (1978). Structural Change in the American Economy, by Functional Industry Group. Review of Income and Wealth, 24(1), 93104.

Britz, W., van der Mensbrugghe, D. (2018). CGEBox - A flexible, modular and extendable framework for CGE analysis in GAMS. Journal of Global Economic Analyis. 3(2), ???

Caron, J., Markusen, J. R., (2014). International Trade Puzzles: a Solution Linking Production and Preferences. The Quarterly Journal of Economics, 1501-1552.

Carter, A.P. (1970). Structural Change in the American Economy, Harvard University Press, Massachusetts

Chenery, H. B., Robinson, S., \& Syrquin, M. (1986). Industrialization and growth (p. 45). The World Bank, Washington.

Corong, E., Hertel, T., McDougall, R., Tsigas, M., \& van der Mensbrugghe, D. (2017). The Standard GTAP Model, Version 7. Journal of Global Economic Analysis, 2(1), 1-119. doi:http:/ /dx.doi.org/10.21642/JGEA.020101AF.

Cranfield, J. A., Preckel, P. V., Eales, J. S., \& Hertel, T. W. (2000). On the estimation of'an implicitly additive demand system'. Applied Economics, 32(15), 1907-1915

Dellink, R., Chateau, J., Lanzi, E., \& Magné, B. (2017). Long-term economic growth projections in the Shared Socioeconomic Pathways. Global Environmental Change, 42, 200-214

Dixon, P.B., M.T. Rimmer (2002). Dynamic General Equilibrium Modelling for Forecasting and Policy: a Practical Guide and Documentation of MONASH. Contributions to Economic Analysis 256, North-Holland Publishing Company, pp. xiv+338.

Dixon, P.B., R.B. Koopman and M.T. Rimmer (2013). “The MONASH style of CGE modeling: a framework for practical policy analysis", Chapter 2, pp. 23-102 in P.B. Dixon and D.W. Jorgenson (editors) Handbook of Computable General Equilibrium Modeling, Elsevier.

Dixon, P.B., B.R. Parmenter, John Sutton and D.P. Vincent (1982), ORANI: A Multisectoral Model of the Australian Economy, Contributions to Economic Analysis 142, North-Holland Publishing Company

Doshi, K. (1994). Determinants of the saving rate: an international comparison. Contemporary Economic Policy, 12(1), 37-45.

Duarte, M., Restuccia, D., (2010). The role of the structural transformation in aggregate productivity. The Quarterly Journal of Economics 125, 129-173. 
Ianchovichina, E. \& McDougall, R., (2000). Theoretical structure of Dynamic GTAP. GTAP Technical Papers. Paper 14

Haraguchi, N., Cheng, C. F., \& Smeets, E. (2017). The importance of manufacturing in economic development: Has this changed? World Development, Vol.93, pp. 293-315.

Harberger, A. C., (1998). A Vision of the Growth Process. The American Economic Review 88 (1), 1-32.

Hertel, T.W. \& Tsigas, M.E. (1997) "Structure of GTAP", in: T.W. Hertel (ed.), Global Trade Analysis: Modeling and Applications, Cambridge University Press.

ICP (2015). Purchasing Power Parities and Real Expenditures of World Economics: A Comprehensive Report of the 2011 International Comparison Program. World Bank, Washington, D.C.

Kirsanova, T., \& Sefton, J. (2007). A comparison of national saving rates in the UK , US and Italy. European Economic Review, 51(8), 1998-2028.

Loayza, N., Schmidt-Hebbel, K., \& Servén, L. (2000). What drives private saving across the world?. Review of Economics and Statistics, 82(2), 165-181.

Lutz, W., Butz, W. P., \& Samir, K. E. (Eds.). (2017). World Population \& Human Capital in the Twenty-First Century: An Overview. Oxford University Press

Masson, P. R., Bayoumi, T., \& Samiei, H. (1998). International evidence on the determinants of private saving. The World Bank Economic Review, 12(3), 483-501.

Matsuyama, K. (2008). Structural change. In S. Durlauf, \& L. E. Blume (Eds.), The New Palgrave Dictionary of Economics (2 ed.). Palgrave-Macmillan.

McMillan, M., Rodrik, D., (2011). Globalization, Structural Change and Productivity Growth. NBER Working Paper w17143.

Muhammad, A., Seale, J. L., Meade, B., \& Regmi, A. (2011). International evidence on food consumption patterns: an update using 2005 international comparison program data. (March 1, 2011). USDA-ERS Technical Bulletin No. 1929. Available at SSRN: $\underline{\text { https://ssrn.com/abstract }=2114337}$ or http:/ / dx.doi.org/10.2139/ssrn.2114337

Riahi, K., Van Vuuren, D. P., Kriegler, E., Edmonds, J., O' neill, B. C., Fujimori, S.,. \& Lutz, W. (2017). The shared socioeconomic pathways and their energy, land use, and greenhouse gas emissions implications: an overview. Global Environmental Change, 42, 153-168.

Rimmer, M. T., \& Powell, A. A. (1996). An implicitly additive demand system. Applied Economics, 28(12), 1613-1622.

Rodrik, D., (2016). Premature deindustrialization. Journal of Economic Growth 21, 133.

Roson R, \& van der Mensbrugghe D. (2018), Demand-Driven Structural Change in Applied General Equilibrium Models, in F. Perali and P. L. Scandizzo (eds.), The New Generation of Computable General Equilibrium Models, Springer International, doi: /10.1007/978-3-319-58533-8_2. 
Roson R. (2019). Sectoral Differences in Labor Productivity Growth: Estimation and Modeling. Research in Applied Economics, Vol. 11(1), pp. 1-8

Sato, R., \& Ramachandran, R. (1980). Measuring the impact of technical progress on the demand for intermediate goods: A survey. Journal of Economic Literature, 18(3), 1003-1024.

Sellers, S., \& Ebi, K. (2017). Climate change and health under the shared socioeconomic pathway framework. International journal of environmental research and public health, 15(1), 3 .

Skolka, J. (1989). Input-output structural decomposition analysis for Austria. Journal of Policy Modeling, 11(1), 45-66.

Swiecki, T. (2017) Determinants of structural change. Review of Economic Dynamics 24, 95-131.

Triplett, J. E., Bosworth, B. P., (2003). Productivity Measurement Issues in Services Industries: Baumol's Disease Has Been Cured. Economic Policy (September), 2333.

Üngör, M., (2013). De-agriculturalization as a result of productivity growth in agriculture. Economics Letters 119, 141-145.

de Vries, G., Timmer, M., de Vries, K., (2015). Patterns of structural change in develop-ing countries. In: Weiss, J., Tribe, M. (Eds.), Routledge Handbook of Industry and Development. Routledge, pp. 65-83.

Van der Mensbrugghe, D. (2005). LINKAGE Technical Reference Document: Version 6.0. World Bank, Washington, D.C..

van der Mensbrugghe, D. (2018). The Standard GTAP Model in GAMS, Version 7. Journal of Global Economic Analysis, 3(1), 1-83. doi:http:/ /dx.doi.org/10.21642/JGEA.030101AF

van Meijl, H., Havlik, P., Lotze-Campen, H., Stehfest, E., Witzke, P., Dominguez, I.P., Bodirsky, B.,van Dijk, M., Doelman, J., Fellmann, T. and Humpenoeder, F., 2017. Challenges of Global Agriculture in a Climate Change Context by 2050 (AgCLIM50). JRC Science for Policy Report, EUR 28649 EN, doi:10.2760/7724

Woltjer, G. B., Kuiper, M., Kavallari, A., van Meijl, H., Powell, J. P., Rutten, M. M., ... \& Tabeau, A. A. (2014). The MAGNET model: Module description (No. 1457). LEI Wageningen UR.

Young, A., (2014). Structural transformation, the mismeasurement of productivity growth, and the cost disease of services. American Economic Review 104 (11), 3635-3667. 